\title{
Cristóbal Colón alias Christoph Columbus und der erste europäische Blick auf die Neue Welt
}

Am Beginn der heutigen Gestalt Amerikas steht, in einem ganz der römischen Antike verpflichteten Sinne, eine Vogelschau. In dem uns von dem Dominikaner Bartolomé de Las Casas (vgl. Abb. 47: Porträt des Bartolomé de Las Casas) überlieferten Bordbuch - denn das handschriftliche Original ist ebenso verschwunden oder verschollen wie der Kopf des Columbus selbst - finden wir, datiert auf den Tag des Herrn, Sonntag den 7. Oktober 1492, einen ganz besonderen Eintrag des Seefahrers. Wir befinden uns an Bord der drei Schiffe, der drei wagemutigen Nussschalen, die noch immer geradeaus nach Westen segeln und in gespannter Erwartung der Sichtung nahen Landes sind, sich zugleich aber auch am Rande der Verzweiflung befinden. So lesen wir im Bordbuch mit der Stimme des Las Casas:

\footnotetext{
Navegó a su camino al Oueste. Anduvieron 12 millas por hora dos horas, y después 8 millas por hora; y andarán hasta una hora de sol 23 leguas; contó a la gente 18. En este día, al levantar del sol, la carabela Niña, que iba delante por ser velera, y andaban quien más podía por ver primero tierra, por gozar de la merced que los reyes a quien primero la viese habían prometido, levantó una bandera en el topo del mástil, y tiró una lombarda por señal que veían tierra, porque así lo había ordenado el Almirante. Tenía también ordenado que al salir del sol y al ponerse se juntasen todos los navíos con él, porque estos dos tiempos son más propios para que los humores den más lugar a ver más lejos.

Como en la tarde no viesen tierra, la que pensaban los de la carabela Niña que habían visto, y porque pasaban gran multitud de aves de la parte del norte al Sudueste, por lo cual era de creer que se iban a dormir a tierra, o huían quizá del invierno, que en las tierras de donde venían debía que querer venir, por esto el Almirante acordó dejar el camino del Oueste, y pone la proa hacia Ouesudueste con determinación de andar dos días por aquella vía. Esto comenzó antes una hora del sol puesto. ${ }^{1}$
}

Da sie am Nachmittag das Land nicht sahen, welches man von der Karavelle Niña aus zu sehen gemeint hatte, und da eine große Menge an Vögeln von Norden her nach Südwesten vorbeizog, so dass man glauben durfte, sie würden zum Schlafen in Richtung Land fliegen oder vielleicht vor dem Winter fliehen, der in den Landstrichen, aus denen sie kamen, wohl bevorstand, vereinbarte der Admiral, vom Weg nach Westen abzuweichen, und er setzt Kurs auf Westsüdwest, entschlossen, für zwei Tage jenen Weg einzuschlagen. Dies begann eine Stunde vor Sonnenuntergang. ${ }^{2}$

1 Colón Cristóbal: Diario de a bordo. Edición de Luis Arranz. Madrid: Historia 16 1985, S. 86 f.

2 Vgl. ebda.

Ә Open Access. (c) 2020 Ottmar Ette, publiziert von De Gruyter. (cc))BY-NC-ND Dieses Werk ist lizenziert unter der Creative Commons Attribution-NonCommericial-NoDerivatives 4.0 Lizenz.

https://doi.org/10.1515/9783110650686-012 
Es war eine vom Flug der Vögel ausgelöste Veränderung des Kurses mit Folgen. Denn diese leichte Kursänderung, die Columbus an jenem denkwürdigen Tag ausführen ließ, und welche die Schiffe, die zuvor direkt nach Westen gesegelt waren, nun in eine südwestliche Fahrtrichtung brachten, hatte weitreichende (und an jenem Tage gewiss nicht überblickbare) Konsequenzen für die sogenannte ,Entdeckung' der Amerikas, die Geschichte ihrer Eroberung und Kolonisation wie auch die geokulturelle und letztlich geopolitische Konfiguration der amerikanischen Hemisphäre. Denn vieles hätte einen völlig anderen Lauf genommen, hätte Columbus seinen direkt nach Westen festgelegten Kurs beibehalten. Aber er tat es nicht.

Hätte Columbus nichts am Kurs verändert und darüber hinaus eine drohende Meuterei auf der dann längeren Fahrtstrecke überstanden, er wäre wohl mit Hilfe des starken Golfstroms an jenem Teile Amerikas gelandet, der uns heute als der Sunshine State bekannt ist: an der Küste Floridas, vielleicht irgendwo beim heutigen Jacksonville. Schon der bekannte US-amerikanische Autor und Columbus-Biograph Washington Irving war auf diese Stelle des Bordbuches gestoßen und hatte in seiner berühmten Darstellung des Lebens des Admirals auf die möglichen Folgen einer Fortsetzung der Fahrt nach Westen aufmerksam gemacht.

Alexander von Humboldt, der wohl beste Kenner der damals zugänglichen Literatur zur Entdeckungs- und Eroberungsgeschichte Amerikas, hatte Irvings Überlegungen zur Kenntnis genommen und seinerseits auf diesen „Umstand von unermesslicher Wichtigkeit“ hingewiesen, „da er den Vereinigten Staaten statt einer protestantischen englischen Bevölkerung eine katholische spanische hätte geben können“. ${ }^{3}$ Die Kursänderung war also eine Sache von welthistorischer Bedeutung: Wir sehen, wie wichtig schon die beiden ersten Dimensionen des Raumes sein können. Columbus selbst ahnte davon freilich nichts: Er hatte nur einen kürzeren Weg nicht zum (amerikanischen) Kontinent, sondern zur (karibischen) Inselwelt gefunden.

Was aber war an Bord der spanischen Schiffe vor sich gegangen? Bereits am 6. Oktober, zu einem Zeitpunkt, als die von Columbus eigenhändig vorgenommenen Fälschungen der Angaben über zurückgelegte Distanzen nichts mehr fruchteten und die erschöpften Mannschaften der drei Karavellen an Widerstand gegen eine Fortsetzung der Fahrt nach Westen dachten, hatte es eine

3 Humboldt, Alexander von: Kritische Untersuchungen über die historische Entwickelung der geographischen Kenntnisse von der Neuen Welt und die Fortschritte der nautischen Astronomie in dem 15ten und 16ten Jahrhundert. Aus dem Französischen übersetzt von Dr. Jul. Ludw. Ideler, Privatdocenten an der Berliner Universität. Bd. 2. Berlin: Nicolai’sche Buchhandlung 1836, S. 111. 
bemerkenswerte Reaktion im Flottenverband gegeben. Kapitän Martín Alonso Pinzón, der als aus der andalusischen Herkunftsregion stammender erfahrener Seemann bei den meisten Matrosen nicht nur seines, sondern auch der beiden anderen Schiffe wohl in höherem Ansehen als der Genuese Columbus stand, hatte an diesem Tag bereits vorgeschlagen, die Fahrtrichtung nach Südwesten abzuändern. Doch Columbus reagierte damals noch schroff. Der Transkription des Bordbuches entnehmen wir an jenem Tag: „al Almirante pareció que no“, ${ }^{4}$ Columbus war strikt dagegen. Und er hielt dies in seinem Bordbuch fest - auch dies ein deutlicher Beleg für ein pragmatisches Verhältnis zwischen Reisen und Schreiben.

Erst am folgenden Tag willigte der künftige Admiral, dessen Name zu Recht mit einem Vogel, der Taube, in Verbindung gebracht wurde, unter Hinweis auf den Flug der Vogelschwärme in eine Änderung der Fahrtrichtung ein. Dabei musste er sein Gesicht wahren, sollte es doch nicht wie ein nachträgliches Einlenken gegenüber Martín Alonso Pinzón aussehen. Er griff dabei, wie Humboldt anmerkte, auf die Erfahrung der Portugiesen zurück, „welche den größeren Theil der Inseln, die sie besitzen“, aufgrund ihrer „Beobachtung des Fluges der Vögel entdeckt“ hätten. ${ }^{5}$ Die Kursänderung hatte also weniger etwas mit Auspizien, mit dem Ritus eines Auguren zu tun, als mit einem spezifischen Erfahrungswissen, das gerade die Portugiesen mehrfach erfolgreich in ihrer Entdeckungsgeschichte eingesetzt hatten. Und doch kann man im Flug der Vögel mehr als einen bloßen Zufall sehen.

Die gereizte Stimmung an Bord der drei Schiffe beruhigte sich nur mühsam. Die Seeleute willigten zunächst in die veränderte Route ein, zumal man auch während der folgenden Tage Zeichen nahen Landes wahrnahm; doch nachdem sie noch während der ganzen Nacht Vögel hatten vorbeifliegen hören, begehrten sie am 10. Oktober gegen Columbus auf, der sie ein letztes Mal mit Versprechungen beruhigen konnte, obwohl die Mannschaft wohl wusste, daß im Grunde ein point of no return erreicht war.

Am folgenden Tag, dem 11. Oktober des Jahres 1492, aber sah ein Matrose namens Juan Rodríguez Bermejo, der unter dem Namen Rodrigo de Triana in Geschichte und Legendenbildung Eingang fand, ${ }^{6}$ das ersehnte Land, eine Meldung,

4 Colón, Cristóbal: Diario de a bordo, S. 86. Die von Colón angeführten Gründe für die Ablehnung sind wenig überzeugend, so dass Luis Arranz in seinem Kommentar zu dieser Passage des Bordbuchs auch zu der Einschätzung gelangte, daß Columbus lediglich dem Eindruck entgegenwirken wollte, er habe diesen Entschluss auf Veranlassung Pinzóns getroffen (Diario de a bordo, S. 87, Fußnote 36).

5 Humboldt, Alexander von: Kritische Untersuchungen, Bd. 1, S. 213.

6 Colón, Cristóbal: Diario de a bordo, S. $88 \mathrm{f}$. 
die sich im Gegensatz zu jener der Niña vom 7. Oktober, bereits am folgenden Tage bestätigen sollte. Kein Zweifel kann bestehen: Es waren die Vögel gewesen, welche die spanischen Karavellen in die Inselwelt der Karibik geführt und damit den weiteren Fortgang der Weltgeschichte nicht unwesentlich mitbeeinflusst hatten. ${ }^{7}$ Nicht zu Unrecht kommentierte Alexander von Humboldt in seinem überwiegend der Figur des Columbus gewidmeten und ursprünglich in französischer Sprache erschienenen Examen critique:

Niemals hat der Flug eines Vogels gewichtigere Folgen gehabt; Denn die Aenderung des Windstriches am 7. Oktober entschied die Richtung, nach welcher die ersten Ansiedelungen der Spanier in Amerika Statt finden sollten und gefunden haben. ${ }^{8}$

Der Traum des Columbus war also wahr geworden - wenn er auch, was er zeitlebens negierte, nicht in Asien angekommen war und die Bewohner dieser Landstriche auch keine Bewohner Indiens, keine indios, waren. An einem Freitag, dem 3. August 1492, hatte Columbus die Segel gesetzt und Europa verlassen, und an einem Freitag setzte er erstmals seinen Fuß auf amerikanischen Boden und entfaltete die Zeichen spanischer Macht. Heilsgeschichtliche Zeichen also überall - für all jene zumindest, die solche Zeichen sehen wollten.

Für den schon bald zum Admiral Aufsteigenden aber konnten diese Zeichen nicht trügen. Es setzte sich die Deutung jener sich dem Blick des Columbus darbietenden signos und señales fort, eine Lektüre, die schon bei Humboldt, vor allem aber dann im Gefolge strukturalistischer und poststrukturalistischer Semiotiken und Semiologien ein ums andere Mal ihrerseits gedeutet wurde. ${ }^{9}$ Vergessen

7 Was, so bliebe noch zu klären, hatte Pinzón auf den Gedanken einer Kurskorrektur gebracht? Humboldt ging auch dieser Frage in Humboldt, Alexander von: Kritische Untersuchungen (Bd. 2, S. 114) nach: „Vallejo, ein aus Moguer gebürtiger Seemann, erzählt ganz naiv in den Proceßverhandlungen, daß 'Pinzon am Abend habe Papageien vorüberfliegen sehen und gewußt habe, daß diese Vögel nicht ohne besonderen Grund nach Süden hinflögen’.“ Daß es sich in den Worten des Seemanns um Papageien handelte, dürfte Humboldt, der Papageien viel abzugewinnen wusste, zusätzlich fasziniert haben; vgl. auch den nicht ganz ernsten Aufsatz des Verfs.: Papageien, Schriftsteller und die Suche nach der Identität. Auf den Spuren eines Vogels von Alexander von Humboldt bis in die Gegenwart. In: Curiosités caraïbes. Festschrift für Ulrich Fleischmann. Berlin 1988, S. 35-40.

8 Humboldt, Alexander von: Kritische Untersuchungen, Bd. 2, S. 114 f. Zur Entwicklung des Columbus-Bildes in den Schriften Alexander von Humboldts vgl. Verf.: Entdecker über Entdecker: Alexander von Humboldt, Cristóbal Colón und die Wiederentdeckung Amerikas. In: Heydenreich, Titus (Hg.): Columbus zwischen zwei Welten. Historische und literarische Wertungen aus fünf Jahrhunderten. Bd. I. Frankfurt am Main: Vervuert Verlag 1992, S. 401-439. 9 Am erfolgreichsten war sicherlich der Band von Todorov, Tzvetan: La conquête de l'Amérique. La question de l'autre. Paris: Les Editions du Seuil 1982. 
wir darüber aber nicht die Tatsache, dass es die Deutung eines Vogelfluges und damit ein Augur - gleichviel, ob es sich dabei um Columbus oder Pinzón handelte - war, der als Interpret der Zeichen am Himmel in gewisser Weise die Konzentration der Spanier auf den Süden und damit die vorübergehende Schaffung eines ‘Leerraumes' im Norden vorgab. Die künftige Zweiteilung der Amerikas war damit gleichsam vorgegeben. Und für Columbus selbst stand fest, dass kein Geringerer als der Dreifaltige Gott ihm in den entscheidenden Momenten seines Reiseberichts Gnade bezeugt und geholfen hatte. Sein Reisetagebuch selbst, das von Anrufungen des Herrn geradezu überquillt, wurde damit zu einem Zeugnis dieser göttlichen Hilfe und Gnade.

Die sich anschließende und reiseliterarisch nachgezeichnete Fahrt des künftigen Admirals der Katholischen Könige durch die amerikanische Inselwelt, die noch ihrer europäischen Namen und ihrer Mehrfachbenennungen als Antillen, als Karibik, als Westindien usw. harrte, wurde - ganz im Sinne Tzvetan Todorovs - zur hermeneutischen Bewegung eines Zeichenlesers, der nicht nur seine Lesarten, sondern selbst seine Zeichen aus der Alten Welt mitgenommen hatte und nun auf die Küstensäume einer ihm noch unbekannten und doch so vertrauten Welt projizierte. Denn Columbus war zwar in einer für ihn und die Europäer seiner Zeit vollständig neuen Welt gelandet; doch möblierte er nicht nur die Dimensionen von Raum und Zeit, sondern auch die kulturellen, geschlechterspezifischen oder fiktionalen Dimensionen seines Reiseberichts ganz so, wie er dies aus der Alten Welt in die Neue zu übertragen vermochte. Dies war der Weg, wie die Alte Welt in die Neue $\mathrm{kam}^{10}$ und die Neue der Alten Welt nicht nur militärisch und politisch, sondern auch kulturell und ideologisch einverleibt wurde. In Columbus‘ Bordtagebuch können wir diesen Prozeß einer Übertragung und Einverleibung der Zeichen in aller Deutlichkeit sehen.

Beschäftigen wir uns an dieser Stelle aber zunächst einmal in aller gebotenen Kürze mit der Biographie jenes Mannes, der bald schon bei seinen Mitbürgern in Spanien verhasst war, obwohl er doch - wie Voltaire dies einmal trefflich formuliert hatte - für seine Zeitgenossen die Werke der Schöpfung verdoppelt hatte. Dies hatte nicht zuletzt mit der Tatsache zu tun, daß Cristóbal Colón, in dessen Name sich der das Christuskind über das Wasser tragende Christophorus, aber auch die Taube sowie der Kolonist, der Kolonisator begegnen, einer jener Männer war, wie sie die sich beschleunigende Zeit am Ende des 15. Jahrhunderts hervorbrachte und die gleichsam von nirgendwo her

10 Vgl. hierzu auch Gewecke, Frauke: Wie die alte Welt in die neue kam. Stuttgart: Klett-Cotta 1986. 


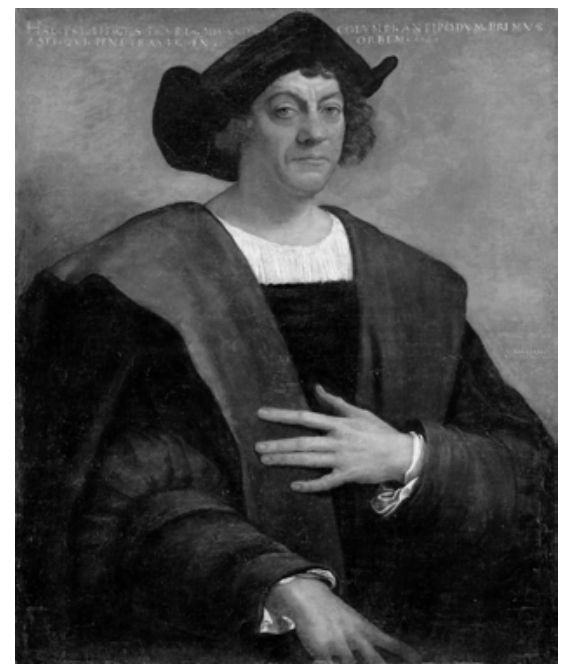

Abb. 38: Cristóbal Colón (Genua, 1451? - Valladolid, 1506).

kamen und in der Geschichte erschienen. Er wurde als Genuese und als Jude, als Mallorquiner und als Portugiese, ja sogar als Schweizer reklamiert und verfügte so über jene Qualitäten, die einen wahren Europäer auszeichnen. Denn er war gewiss kein Spanier und war auch gewiss des Spanischen nicht wie einer Muttersprache mächtig, verstand es aber bravourös, als ein Europäer die Hypothese seiner verschiedenen Herkünfte vor allem für seine Laufbahn, für seine Zukünfte nutzbar zu machen. Seine Projekte und Pläne hätte er auch anderswo in die Tat umgesetzt: Spanien war nach Portugal ohnehin nur seine zweite Wahl gewesen. Wer aber war dieser Cristóbal Colón alias Cristoforo Colombo alias Cristóvão Colombo alias Christopher Columbus wirklich? Sehen wir uns kurz sein Leben bis zum Aufbruch seiner ersten Expedition nach Indien, China und das Cipango (Japan) Marco Polos an.

Der spätere Entdecker Amerikas lebte wohl von 1451 bis 1506, eine Zeitspanne, in welcher sich die Welt entscheidend veränderte und nicht mehr war, was sie um die Mitte des 15. Jahrhunderts einst gewesen ist. Die wahrscheinlichste Version seiner Geburt ist, dass er 1451 in der Nähe des italienischen Genua die Welt erblickte, im selben Jahr übrigens wie die spanische Königin Isabel la Católica und jener andere Italiener, welcher dem neu entdeckten Kontinent den Namen einer 'Neuen Welt' zusprach, Amerigo Vespucci. Er war damit ein Jahr älter als Fernando el Católico oder Leonardo da Vinci und war erst zwei Jahre alt, als das Oströmische Reich und damit das alte Konstantinopel unterging. Mit der Ausbreitung des Osmanischen Reiches aber waren die direkten 
Handelswege zwischen Europa und Indien beziehungsweise China unterbrochen: die begehrten orientalischen Luxusgüter gelangten nunmehr nur noch mit hohen Aufschlägen in die Zentren Europas.

Doch zurück zu unserem jungen Genuesen. Spätestens im Jahre 1469, nach eigener Aussage aber bereits mit vierzehn Jahren sehen wir ihn zur See auf ersten Handelsreisen durch das Mittelmeer. Er soll kurzzeitig an der Universität von Pavia studiert haben, eine Tatsache, die durch seine Bekanntschaft mit dem Latein und seine kartographischen wie kosmographischen Kenntnisse gestützt wird.

Cristóbal Colón trieb sich schon als Jugendlicher auf Schiffen herum, lernte das Handwerk sozusagen von der Pieke auf, fuhr zunächst auf genuesischen Handelsschiffen, stieg dann bald zum Kapitän auf, kannte sich hervorragend aus in den verschiedenen Routen im Mittelmeer, Kenntnisse, die er dann später zu nutzen verstand, als er zum Teil im Sold der Genuesen oder mit diesen verbündeten Königreichen, zum Teil auch wohl auf eigene Rechnung zum Korsaren wurde, der im Mittelmeer auch vor Angriffen auf feindliche Schiffe in einem rechtlichen Niemandsland nicht zurückschreckte. In einer dieser Auseinandersetzungen erleidet er 1476 Schiffbruch vor der Küste Portugals. Er kann jedoch aus eigener Kraft, festgeklammert an ein Ruder des von ihm befehligten, aber untergegangenen Schiffes, an Land schwimmen und deutet seine Rettung später als ein erstes großes Zeichen Gottes.

Lange Jahre lebte Columbus nun in Portugal, in jenem Land, das ohne jeden zweifel über die besten Voraussetzungen für große umfangreiche Expeditionen in unbekannte Gewässer, über die besten Wissenschaftler, ein derartigen Plänen stets offenstehendes Königshaus, über hervorragende Instrumente und nicht zuletzt einen hohen Grad an Geheimhaltung verfügte. Jegliche territoriale Expansion blieb Portugal aufgrund der Existenz Spaniens, das noch immer mit der Reconquista beschäftigt war, verwehrt: Die einzige Expansionsmöglichkeit war für Portugal das Meer, und diese Politik, die Portugal konsequent seit Heinrich dem Seefahrer verfolgte, brachte dem Land seine Bedeutung und auch seinen jahrhundertelangen Reichtum ein. Portugal war für einen Columbus im Grunde ideal.

Seit 1477 lebte Columbus zusammen mit seinem Bruder Bartolomeo in Lissabon. In der europäischen Seefahrernation par excellence dient er sich langsam hoch und unternimmt unter anderem Reisen nach England und Island, nach Madeira und auf die Azoren, 1482 selbst nach São Jorge da Mina an der westafrikanischen Küste. Bei diesen Fahrten lernte er, wie man mit den starken Strömungen in diesen Gewässern, mit den wesentlich höheren Wellen und überhaupt mit jenem weiten Meeresbereich umgehen muss, den die Portugiesen in einem weit nach Westen ausholenden Bogen kreuzen mussten, um in ihr Heimatland, nach Lissabon, zurückzukommen. 
Auf diese Weise erfuhr Columbus von den jahreszeitlich sehr konstant blasenden Passatwinden und mehr noch von den Gefahren jener Windstillen, jener Kalmen in den sogenannten Rossbreiten, die Schiffe und Mannschaften oft für Wochen und Monate festhielten, weil kein Windchen blies und die Mannschaften langsam an Skorbut krepierten. Columbus wusste zugleich aber auch, dass diese Meere sehr wohl zu befahren waren. Dem Seemannsgarn von einem koagulierenden, jegliches Schiff festhaltenden Meer schenkte er keinerlei Glauben.

So weiten sich seine Kenntnisse aus. Bereits 1479 vermählt er sich mit Dona Filipa Perestrelo Moñiz, die aus einer adeligen Familie stammt, ihm die Türen der gesellschaftlichen Elite Portugals öffnet und mit der er einen Sohn namens Diego hat. Für einige Zeit lebt er auf Porto Santo, wo sein Schwiegervater Gouverneur gewesen war und wo Columbus nun Seekarten und Logbücher studierte. In dieser Zeit muss der Plan entstanden sein, Indien nicht auf dem Weg um das Kap der Guten Hoffnung, sondern auf dem Westweg zu erreichen. Doch es gelingt ihm nicht, den portugiesischen Hof von seinen hochfliegenden Plänen $\mathrm{zu}$ überzeugen, den Orient auf dem Westweg mit Europa zu verbinden. So wendet er sich Spanien zu.

Er begibt sich 1485 nach Kastilien, auf der Suche nach anderen Partnern für sein gewagtes Unternehmen; doch ein erstes Treffen mit den Katholischen Königen im Jahre 1486 führt zu keiner Übereinkunft. Unterdessen gelingt es Bartolomeu Diaz 1488, für die portugiesische Krone das Kap der Guten Hoffnung zu umrunden. Nunmehr dominieren die Portugiesen unangefochten die Ostroute in den Orient unter Umschiffung Afrikas. Weitere Gespräche mit der portugiesischen Krone scheitern so wie alle Versuche, die Höfe Frankreichs oder Englands für sein Vorhaben zu begeistern. Christoph Columbus beginnt, zunehmend zu verzweifeln.

Doch dann der Durchbruch: Im August 1492 kommt es zu einer Übereinkunft mit den Katholischen Königen, wobei Isabel hier eine entscheidende rolle spielte: Die Capitulaciones de Santa Fé werden zwischen Columbus und der spanischen Krone abgeschlossen. Fortan sind nur noch technische Details zu klären: Jetzt endlich ist der Weg nach Westen frei für den Genuesen, den wir in unserer Vorlesung mitten in der Karibik zurückgelassen hatten.

Doch bevor wir nun die einzelnen Textpassagen - insbesondere aus dem ersten Bordbuch des Christoph Columbus oder Cristóbal Colón - analysieren und interpretieren wollen, sollten wir uns einen Überblick über die Reisen dieses Mannes - insgesamt vier waren es gewesen - in jene Welt verschaffen, der dann ein anderer seinen Namen geben sollte. Es ist nicht immer leicht, bei diesen vier Reisen den Überblick zu behalten. 


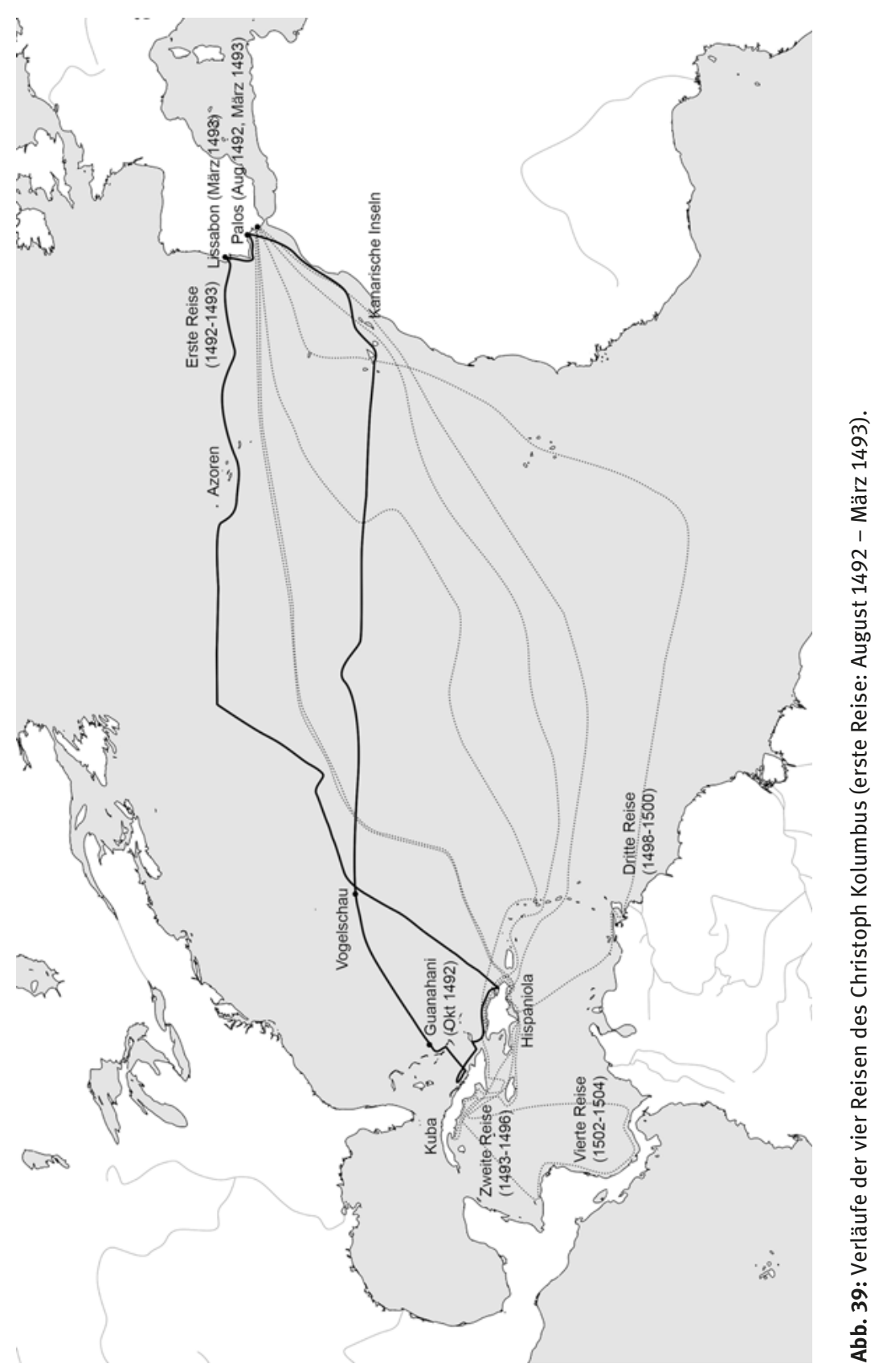


Der Beginn der ersten Expedition des Columbus erfolgte im andalusischen Palos am 3. August 1492; man kehrte am 15. März 1493 wieder zurück. Die gesamte Expedition verfügte über eine Nao und zwei Karavellen. An Bord befand sich auch der später berühmte und einflussreiche Juan de la Cosa, der im Jahre 1500 die erste Weltkarte einschließlich Amerikas entwarf, eine Karte, die wir schon gesehen und besprochen haben (vgl. Abb. 15: Mapamundi des Juan de la Cosa). Auf der Pinta war Martín Alonso Pinzón Kapitän, auf der Niña war es Vicente Yáñez Pinzón - allein dies macht schon deutlich, dass Columbus ein starkes andalusisches Brüderpaar entgegenstand. Von den insgesamt wohl 90 Mann sind 87 namentlich bekannt; 40 Mann waren es wohl auf dem Flaggschiff, der Santa Maria, jeweils 25 Mann Besatzung auf den kleineren und wendigeren Karavellen. Die Mannschaft stammte überwiegend aus Palos, Moguer und Huelva, dazu kamen einige Basken und Galizier sowie eine kleine Gruppe von Ausländern, darunter ein Kalabrese, einVenezianer und ein Schwarzer. Als Dolmetscher fungierte ein konvertierter Jude, Luis de Torres, der ein Experte für orientalische Sprachen, Arabisch und Hebräisch war. Man hoffte, damit sprachlich auf alle Eventualitäten vorbereitet zu sein. Mit den Sprachen eines neuen Kontinents hatte niemand gerechnet: Die amerikanischen Sprachenfamilien waren den Europäern noch gänzlich unbekannt.

Der in allen Seemannsdingen sehr erfahrene Columbus wusste, dass er nach allem ihm zur Verfügung stehenden Informationen bei dieser Reise den Ostwind nutzen musste, der von den Kanaren ab recht zuverlässig wehte. Er allein konnte einen sicheren Transport nach Westen garantieren. Doch landete man nicht auf Tenerife, wo die Spanier noch immer Krieg mit den Guanchen führten - die Eroberung der Kanaren war noch nicht abgeschlossen -, sondern auf La Gomera, wo man die Vorräte auffüllte und von wo aus man am 6. September 1492 wieder in See stach. Auf La Gomera zeigt man noch heute den Löffel, mit dem Columbus gegessen haben soll. Mit dem Passieren der westlichsten Kanaren-Insel Hierro, die für lange Zeit den Nullmeridian der spanischen Kartenwerke lieferte, begann dann am 8. September die Überfahrt. Am 12. Oktober ging man nach dreiundreißigtägiger Überfahrt in Guanahani an Land. Wahrlich kein Wunder, dass man die 33 Tage der Überfahrt mit den 33 Lebensjahren von Jesus Christus in Verbindung brachte. Wie auch immer: Die kleine spanische Expedition befand sich jetzt in einer neuen Welt: nicht zwischen den Vor-Inseln, den Antillen, von China, Indien und Cipango, sondern in einer völlig neuen, nicht mehr altweltlichen Umgebung. Wie sagte ein englischsprachiger Kollege einmal so schön? In the beginning, America was in the way.

Doch Amerika stand für Columbus nicht im Weg: Es war seine Rettung! Denn er hatte den Umfang der Erdkugel weitaus zu gering berechnet, ein 
Fehler, der ihm übrigens von den portugiesischen Kommissionen vorgehalten wurde, die seinen Plan ablehnten. Nicht alle Kommissionen bestanden folglich aus bornierten Akademikern, die einen so einfachen Plan wie den des Columbus einfach nicht akzeptieren wollten und etwas dagegen gehabt hätten, dass die Erde keine Scheibe, sondern eine Kugel wäre. Dies sind Märchen, die später rund um die Heldentat des Columbus erfunden und erzählt wurden.

Nein, der Fehler hatte bei Columbus System - aber sein Plan hatte an der entscheidenden Stelle Glück: das sprichwörtliche Glück des Tüchtigen. Wäre Amerika nicht im Weg gewesen, dann wäre Columbus ins Nirgendwo gesegelt, ohne jede Chance auf Rückkehr nach Europa. Man hätte nie mehr von ihm gehört. So aber befand man sich inmitten einer Welt, in welcher die Dinge für die Europäer neu sortiert werden mussten. Und damit begann man unverzüglich: Die sogenannte 'Entdeckung' ging mit der territorialen Erfassung und Kolonisierung Hand in Hand.

Erwähnt sei an dieser Stelle nur kurz, dass Columbus am 27. Oktober die Insel Cuba entdeckte und zunächst für einen Kontinent hielt. Am Weihnachtsabend des Jahres 1492 erlitt Columbus Schiffbruch mit seinem Flaggschiff, der Santa María, und ließ mit den Wrackteilen die Befestigung 'La Navidad' errichten. Es war die erste Befestigung von Spaniern in der Neuen Welt. Columbus ließ dort 33 Spanier zurück, von denen kein einziger überleben sollte. Am 6. Januar, am Dreikönigstag also, beginnen dann die Pinta und die Niña langsam mit der Rückreise nach Europa. Doch schon am 14. Januar werden beide Schiffe - vielleicht auch absichtsvoll von Martín Alonso Pinzón gelenkt - voneinander getrennt. Sie werden auf unterschiedlichen Routen die iberische Halbinsel erreichen. Auch Pinzón kehrte zurück, doch von ihm sprach niemand: Der ganze Ruhm gehörte dem Cristóbal Colón.

Am 4. März des Jahres 1493 wird Columbus mit der Niña die Mündung des Tejo erreichen und sich mit dem portugiesischen König austauschen. Die Portugiesen wussten nun, dass der Plan des Columbus aufgegangen war. Die machtpolitischen Konsequenzen waren freilich noch nicht ganz überschaubar, auch wenn sich bald die welthistorische und zugleich weltpolitische Bedeutung des kolumbinischen Unternehmens herauskristallisieren sollten. Am 15. März traf Columbus mit seinen Männern dann wieder in Palos ein. Doch das entscheidende Treffen stand ihm noch bevor: Ende April 1493 wird Cristóbal Colón in Barcelona von den sich dort aufhaltenden Katholischen Königen triumphal empfangen: Er ist auf der Höhe seines Ansehens.

Nebenbei bemerkt: Bald schon werden in eben diesem Barcelona die Symptome einer neuen Krankheit entdeckt, gegen die für lange Zeit keine Mittel zur Verfügung stehen sollten. Es ist die Syphilis, die erste Globalisierungskalamität 
und -epidemie, welche die erste Phase beschleunigter Globalisierung ${ }^{11}$ ganz so begleiten sollte wie AIDS unsere vierte Phase beschleunigter Globalisierung. Wir wissen heute aus der historischen Epidemologie wie auch durch viele zeitgenössische Zeugnisse, dass sich die sexuell ausgehungerte Besatzung von Columbus über die Bordelle der Stadt hermachte und binnen kürzester Zeit die Grundlagen für eine sich rasch verbreitende Pandemie legte, die nicht nur die verschiedensten Länder Europas, sondern auch Afrikas und Asiens erfasste. Für die Portugiesen war es die spanische Krankheit, für die Spanier die französische Krankheit, für die Franzosen die italienische Krankheit und für die Araber die jüdische Krankheit; wir aber wissen heute, dass sie von Barcelona ausging und aufs Engste mit dem triumphalen Einzug des Columbus in die katalanische Hafenstadt zusammenhing.

In Barcelona übergab Columbus den spanischen Königen das Original seines Bordtagebuches und erhielt im Gegenzug wenig später eine Abschrift desselben. Doch Original und Kopie teilten dasselbe Schicksal: Sie sind ganz einfach verschwunden und tauchten in den langanhaltenden rechtlichen Auseinandersetzungen zwischen Columbus und der spanischen Krone nicht mehr auf. Offensichtlich hatte man sie beiseite geschafft. Glücklicherweise fertigte der schon erwähnte Fray Bartolomé de las Casas für seine umfangreiche, im wahrsten Sinne monumentale Historia de las Indias, ${ }^{12}$ einen 'Sumario' an, eine sehr präzise Abschrrift, der wir unsere heutigen Kenntnisse des Bordtagebuches verdanken.

Dabei kann man zwischen drei verschiedenen Teilen dieser Abschrift des Bordtagebuchs unterscheiden: Erstens den wortwörtlichen Zitaten, zweitens den indirekten Zitaten in der dritten Person, die Las Casas einführte, und drittens den Interpolationen des Dominikaners, der das kommentiert, was er gerade transkribiert hat. Manches ließ Las Casas auch aus, passte es doch nicht in den Augen des Dominikaners zur Größe des Columbus. Dies also ist unsere Textgrundlage. Und wir wollen uns im Wesentlichen auf die erste Reise des Christóbal Colón, auf seine erste 'Entdeckungsreise', konzentrieren.

Beschäftigen wir uns also in der Folge mit einer kleinen Auswahl aus den wichtigsten Passagen des Diario, des sogenannten Bordtagebuches des Columbus. Nach der wohlinszenierten Hervorhebung des reiseliterarischen Ortes der Ankunft, die wir schon näher gesehen haben, folgt in Columbus' (Selbst-) Stilisierung ein Höhepunkt dem anderen, wobei nicht nur die räumlichen, sondern

11 Vgl. hierzu die näheren Ausführungen in Ette, Ottmar: TransArea. Eine literarische Globalisierungsgeschichte. Berlin - Boston: Walter de Gruyter 2012, S. 53-104.

12 Vgl. Las Casas, Bartolomé de: Historia de las Indias. Edición de Agustín Millares Carlo y estudio preliminar de Lewis Hanke. 3 Bde. México: Fondo de Cultura Económica 1986. 
vor allem die fiktionale beziehungsweise mythologische Dimension des Reiseberichts deutlich vor Augen tritt.

So findet sich, um nur ein besonders aufschlussreiches Beispiel anzuführen, unter dem 15. Januar 1493 in Las Casas' Transkription die folgende Eintragung, die uns darauf verweist, dass die Rückkehr immer schon in die Ausfahrt des Columbus eingeschrieben ist und daher diese Kreisstruktur stets auch jahrhundertelang die hermeneutische Bewegung und Annäherung der Europäer an die Neue Welt grundlegend prägte und beschrieb. Die Kreisstruktur umschreibt die Route des Columbus, aber auch jeglicher kolonialer Unternehmung, wird doch erst von Europa her das Netz an Gratifikationen und Anerkennungen zugänglich, an welchem der Protagonist einer derartigen Reise interessiert ist. An jenem 15. Januar finden wir also folgenden Eintrag im berühmten Bordbuch:

Dice que se quiere partir porque ya no aprovecha nada detenerse, por haber pasado aquellos desconciertos (debe decir del escándalo de los indios). Dice también que hoy ha salido que toda la fuerza del oro estaba en la comarca de la Villa de la Navidad de Sus Altezas, y que en la isla de Carib había mucho alambre y en Martinino, puesto que será dificultoso en Carib, porque aquella gente diz que come carne humana, y que de allí se parecía la isla de ellos, y que tenía determinado de ir a ella, pues está en el camino, y a la de Martinino, que diz que era poblada toda de mujeres sin hombres, y ver la una y la otra, y tomar diz que algunos de ellos. Envió el Almirante la barca a tierra, y el rey de aquella tierra no había venido porque diz que la población estaba lejos, mas envió su corona de oro como había prometido, y vieron otros muchos hombres con algodón y con pan y ajes, todos con sus arcos y flechas. Después que todo lo hubieron resgatado, vinieron diz que cuatro mancebos a la carabela, y pareciéronle al Almirante dar tan buena cuenta de todas aquellas islas que estaban hacia el Leste, en el mismo camino que el Almirante había de llevar, que determinó de traer a Castilla consigo. Allí diz que no tenían hierros ni otro metal que se hobiese visto, aunque en pocos días no se puede saber de una tierra mucho, así por la dificultad de la lengua, que no entendía el Almirante, sino por discreción, como porque ellos no saben lo que él pretendía en pocos días. Los arcos de aquella gente diz que eran tan grandes como los de Francia e Inglaterra; las flechas son propias como las azagayas de las otras gentes que hasta allí había visto, que son de los pimpollos de las cañas cuando son simiente, que quedan muy derechas y de longura de una vara y media [...]. ${ }^{13}$

13 Colón, Cristóbal Colón: Diario de a bordo, S. 191: „Er sagt, er wolle aufbrechen, da es keinen Sinn mache, sich länger aufzuhalten, insofern man jenes Durcheinander erlebt habe [gemeint ist der Skandal der Indianer]. Er sagt auch, er habe heute erfahren, dass sich die ganze Kraft des Goldes im Gebiet von Villa de Navidad Ihrer Königlichen Hoheiten befände, und dass es auf der Insel Carib viel Metall gebe und auf Matinino, wobei es schwierig auf Carib sein werde, da jene Leute, wie er sagt, Menschenfleisch essen, und dass von dort aus die Insel dieser Leute auftauche, und er habe beschlossen, dorthin aufzubrechen, da sie auf dem Wege liege, sowie nach Matinino, von dem er sagt, es sei ganz von Frauen ohne Männer bevölkert, und er wolle beide Inseln sehen und, wie er sagt, einige ihrer Bewohner mit sich nehmen.“ 
Es ist in dieser Passage sehr spannend zu beobachten, inwiefern Columbus sein Hauptaugenmerk auf die möglichst genaue Deskription aller Phänomene und Sachverhalte richtet, genauestens im Rahmen seiner Möglichkeiten alles beschreibt, um dann aber wenig später, gleichsam im selben Atemzug, die Möglichkeiten $\mathrm{zu}$ erörtern, eben diese Aspekte für die Europäer nutzbar und ausbeutbar zu machen. Wenn im Zentrum dieses Diskurses jeweils das aprovechar, der eigene Nutzen, steht, dann integriert diese Passage zugleich doch eine Höchstzahl an mythologischen Themen und Vorstellungen, die wie in einem sich drehenden Kaleidoskop immer wieder erörtert werden.

Lage und Ausbeutbarkeit von Gold und anderer Edelmetalle werden auch im Lichte ihrer Erreichbarkeit, der Wildheit und Angriffslust der dort lebenden Stämme betrachtet. Hier fließen Versatzstücke antiker Diskurse und Mythen mit ein, deren Wahrheitsgehalt ebenso hoch $\mathrm{zu}$ sein scheint wie die übrigen Deskriptionen aus der Feder des Columbus. Schließlich erscheint auch der Plan des Genuesen, einige Eingeborene nach Europa mitzunehmen, um sie an geeigneter Stelle bei den Katholischen Königen als Belege des Geschriebenen und Beschriebenen vorzuführen. Auch dies sollte Columbus in der Tat nicht nur ankündigen, sondern auch ausführen: So wurden die deportierten indigenen Bewohner der Inseln auch beim triumphalen Einzug des Columbus in die Stadt Barcelona gleichsam als Trophäen im Gefolge mitgeführt.

Der künftige Admiral vergisst dabei nicht, auf Schwierigkeiten seiner Mission hinzuweisen, verstehe er doch etwa die Sprache nicht, die auf diesen Inseln gesprochen werde. Darüber hinaus beschreibt er die Waffen der indigenen Bevölkerung, um gerade auch bei einer zweiten Expedition entsprechend vorbereitet zu sein und die indigenen Stämme bekämpfen zu können. Und in der Tat: Die zweite Expedition des Columbus sollte die Macht des Admirals und seiner Auftraggeber, der Katholischen Könige, vehement unterstreichen: Niemals zuvor und niemals danach würde Columbus über eine derartige Flotte und Streitmacht verfügen.

Die obige Passage zeigt im Übrigen deutlich, auf welche Weise sich bereits im Bordbuch der ersten Reise Bruchstücke geographischer Vorstellungen und Illusionen, etymologischer Fehldeutungen, aus der griechischen Antike stammender Mythen oder ganz materiell orientierter Wunschträume $\mathrm{zu}$ einer bricolage formieren, in welcher Goldgier, Amazonentrauma, Anthropophagieangst und Benennungslust als Stationen und Elemente eines Weges erscheinen, den Columbus nicht aus den Augen verliert, führt er ihn doch zurück nach Spanien, zur Verkündigung des von ihm Gesehenen - und zum Entwurf jener amerikanischen Träume, die sich von Beginn an als komplexe Verschachtelung und Vergleichzeitigung abendländischer Kulturfragmente $\mathrm{zu}$ erkennen geben. Columbus schafft sich seine eigene Welt: eine Welt, in 
welcher die Alte auf ganz direktem Wege in die Neue kommt und diese gleichsam kannibalisiert.

Der indische und orientalische, im Grunde aber amerikanische Traum des Columbus steht im Zeichen der Fülle, ja der Überfülle, stets aber auch im Zeichen einer ganz bestimmten Bewegungsfigur, die wir bereits kennengelernt hatten. Denn die Ankunft enthält bei Columbus immer schon die Rückkehr, die Fahrt durch die Inselwelt immer schon deren Verlassen: Die Kreisstruktur beherrscht als topographische wie als hermeneutische Figur die gesamte Dynamik dieses ersten Reiseberichts aus Amerika. Und als hermeneutische Bewegung gibt sie dem Verstehen des Columbus in seiner Zirkelhaftigkeit jenen Raum, der sich symbolisch mit allerlei abendländischen Versatzstücken zu füllen beginnt.

Erst die Rückkehr nach Europa - und die sich anschließenden frühen Berichte von jener Entdeckung - machen es möglich, dass sich fortan ein Gutteil der Neuen in der Alten Welt bildet. ${ }^{14}$ Die Rückkehr erst gibt der Reisebewegung des Columbus ihren Sinn, ihren sens, ihre eigentliche Richtung. Nicht nur im Zeichen des Kreuzes, sondern auch im Zeichen des Kreises werden die amerikanischen Träume zwanghaft und zwangsweise in amerikanische Wirklichkeiten verwandelt. Columbus macht seinem Namen alle Ehre: Als Christusträger bringt er nicht nur den christlichen Heiland in die Neue Welt, sondern auch alle okzidentalen Attribute, die in der Alten Welt über lange Jahrhunderte Gestalt angenommen hatten.

Mit der Expedition des Christoph Columbus veränderte sich die Weltgeschichte auf eine radikale Weise. Bestimmte westeuropäische Mächte stiegen zu Weltmächten auf, alle Parameter von Politik und Ökonomie, aber auch von Kunst und Kultur veränderten sich im Zeichen der ersten Phase beschleunigter Globalisierung grundlegend. Der berühmte Aphorismus des Georg Christoph Lichtenberg, demzufolge der Tag, an dem der Indianer Columbus entdeckte, ein schlechter Tag für den Indianer gewesen sei, erwies sich bald nicht mehr nur in der künftig als Karibik bezeichneten Region als eine grausame Wahrheit, die durch die Umkehrung der Entdeckungsmetaphorik zum Vorschein gebracht wurde. Europa begann schon bald, zielstrebig die anderen Kontinente, die anderen 'Welten' an die jeweils eigenen Systeme anzuschließen.

Das sich an den 'Indianern' vollziehende Genozid erfasste rasch auch die Bewohner des Festlands - nicht nur jener Insel Cuba, die Columbus für Festland hielt und seinen Männern den Schwur auf diesen Glauben abverlangte, sondern auch jener Küsten, die ein gewisser Amerigo Vespucci als Küstensäume eines Kontinents, einer Neuen Welt, erkannte. Bereits im Jahre 1500 als weiter südlich aufgrund eines Sturms die nach Osten ragende Spitze des

14 Vgl. hierzu Gewecke, Frauke: Wie die neue Welt in die alte kam. Stuttgart: Klett - Cotta 1986. 
heutigen Brasilien von den Portugiesen eher zufällig 'entdeckt' und in Besitz genommen wurde - nahmen die amerikanischen Träume kartographische Gestalt an in jener Karte, die Juan de la Cosa, der Columbus auf dessen zweiter Reise begleitet und zusammen mit Vespucci auch an der Expedition Alonso de Ojedas 1499 teilgenommen hatte, entwarf. ${ }^{15}$

Auch wenn wir uns mit dieser und anderen Weltkarten schon ausführlich beschäftigt haben, gilt es doch kurz festzuhalten: Hier entstanden die Umrisse und Konturen einer Weltregion, in deren Zentrum sich eine Inselwelt befindet, deren Erkundung schon weiter fortgeschritten war, und die den südlichen mit dem nördlichen Teil des Kontinents verbindet. Die Inseln der Karibik wurden zur Drehscheibe der Erschließung und Kolonisierung, der Eroberung und Unterwerfung durch Spanien und nachfolgend auch weitere europäische Mächte. Dabei ist auf der Karte von Juan de la Cosa der Norden des karibischen Beckens, des amerikanischen Mittelmeers, als Besitztum der Katholischen Könige markiert und festgehalten. Dieses mapping der Neuen Welt beinhaltete von Beginn an ein neues mapping der Alten Welt. Eine Welt entstand, in welcher die Alte Welt ohne die Neue Welt nicht mehr vorstellbar war.

Erkundungsfahrten von Francisco Hernández de Córdoba und Juan de Grijalva in den Jahren 1517 und 1518 bringen größere Klarheit über den Küstenverlauf und zugleich die Spanier erstmals in Kontakt mit einer wohlorganisierten und ausdifferenzierten indigenen Gesellschaft: der Gesellschaft der Azteken. Kurze Zeit später vollzieht sich die Eroberung jenes Reiches von Anáhuac mit seinem Zentrum Tenochtitlán, das die Männer um Hernán Cortés zwischen 1518 und 1521 unter Ausnutzung der Gegensätze und Feindseligkeiten zwischen den verschiedenen indianischen Völkern in ihre Gewalt bringen sollten. Fast nahtlos war die Reconquista der iberischen Halbinsel in die Conquista der außereuropäischen Welt Amerikas übergegangen. Der Aufstieg Spaniens von einer sich konstituierenden und seine arabischen ${ }^{16}$ wie jüdischen Wurzeln ausradierenden Regionalmacht zu einer die Welt mit Portugal bald aufteilenden Weltmacht vollzog sich mit ungeheurer Wucht.

Doch kehren wir zum sogenannten Diario de a bordo, jenem Tagebuch zurück, das Tag für Tag die Eintragungen des Columbus (zumindest in Las Casas'

15 In seinen Kritischen Untersuchungen (Bd. 1, S. 16f.) machte Humboldt darauf aufmerksam, dass er zusammen mit Walkenaer 1832 „das Vergnügen“ gehabt hatte, „den Urheber und das Datum“ dieser Karte der Neuen Welt zu erkennen. Die Leistung des preußischen Gelehrten für die kritische Aufarbeitung der spanischen 'Entdeckungsgeschichte' sowie die Aufdeckung der Rolle des Martin Waldseemüller können schlechterdings nicht unterschätzt werden.

16 Vgl. hierzu die umfassende Studie von Walter, Monika: Der verschwundene Islam? Für eine andere Kulturgeschichte Westeuropas. Paderborn: Wilhelm Fink Verlag 2016. 
Transkription) festhielt und uns einen einmaligen Anschauungsunterricht bezüglich des Umgangs der Europäer mit der Erfahrung einer neuen, ihnen zuvor unbekannten Welt gewährt. Denn dieses Bordtagebuch enthält in nuce viele jener Diskurse, welche Europa ermächtigten und legitimierten, seine sich über verschiedene Phasen erstreckende Herrschaft über die Welt anzutreten. Denn Columbus war in jeglichem Sinne ein Europäer.

Wir sollten dabei nunmehr einen das Projekt des Columbus als Ganzes umfassenden Blick einnehmen. Wir hatten bereits die Tatsache gestreift, dass Columbus' Herkunft letztlich doch recht eindeutig nach Genua weist. Seine Vorfahren scheinen 1391 von Spanien nach Italien geflohen zu sein, waren sie doch wohl jüdischer Abstammung und mussten vor den Verfolgungen und Pogromen in ihrer spanischen Heimat fliehen. Der weitere Lebensweg der drei Brüder Colombo, wie sie als solche auch in den Registern und Akten auftauchen, die von einer italienischen Kommission vor mehr als hundert Jahren aufgetrieben wurden, ist dann freilich ein gesamteuropäischer.

Dies scheint mir in der Tat wichtig zu sein. Insoweit haben die ganzen Querelen und Streitereien, ob Columbus nun Genuese, Spanier, Katalane, Portugiese, Mallorquine oder auch Schweizer war, einen großen Vorteil: Sie machen nicht nur darauf aufmerksam, daß sich die einzelnen europäischen Nationen förmlich um ihn stritten, sondern zeigen auch, dass sein ganzer Lebensbereich letztlich ein gesamteuropäischer, freilich mit klarem Schwerpunkt im Mittelmeerraum, war. Nicht umsonst erfolgte die Geburt Europas als Weltmacht vom Becken des Mittelmeeres aus.

Viele Geschichten und Anekdoten ranken sich um den Plan des Columbus, Indien nicht über das Kap der Guten Hoffnung, sondern über den Westweg übers Meer zu erreichen. In neuerer Zeit tauchten erneut Mutmaßungen auf, dass dies nicht unbedingt seine eigene Idee gewesen sei, sondern dass er aus direkten Quellen, von Informanten erfahren habe, dass man auf der anderen Seite dieser immensen Meeresfläche in der Tat Länder und Menschen erwarten durfte. Die aus diesem Bereich wohl wahrscheinlichste These ist die, dass Columbus irgendwo auf seinen Reisen, vielleicht aber auch in einer Hafenkneipe in Lissabon, den sogenannten piloto anónimo getroffen haben soll, der diese Überquerung des Ozeans bereits bewerkstelligt hatte und vor seinem Tode sein Geheimnis noch rasch Columbus anvertraut haben soll. Pure Spekulation also.

Eine zweite These geht davon aus, dass Indianer - und mehr noch Indianerinnen, ja eigentlich Amazonas-Indianerinnen, die Colón als der griechischen Antike entsprungene Amazonen verstanden hätte - von einem Sturm aufs offene Meer hinausgetrieben worden seien und dann irgendwo auf der Höhe der Azoren oder wo auch immer im Südatlantik aufgefischt worden wären; Columbus habe 
dadurch Kunde erhalten von der Existenz größerer Landmassen im Westen. Wie Sie sehen: pure Spekulation auch dies.

Ich glaube nicht daran, dass Columbus tatsächlich dieses predescubrimiento, die der seinigen vorangehende Entdeckung, brauchte, um seine eigenen Pläne von einer Erkundungsfahrt nach Westen zu entwickeln. Denn der mittlerweile erfahrene Seemann hatte längst damit begonnen, alle vorhandenen Informationen $\mathrm{zu}$ sichten und zugleich auch die antiken und neueren Berichte $\mathrm{zu}$ sammeln, in welchen die abendländischen Kosmologen ihre Vorstellungen von der Erde entwickelt hatten. Eventuelle Studien an der Universität von Pavia, von denen sein Sohn berichtete, wären hierfür eine gute Hilfe und Vorbereitung gewesen.

Ich kann an dieser Stelle leider nicht sehr umfänglich auf diese Studien der antiken und jüngeren Quellen durch Columbus eingehen. Der Genuese, dies gilt es festzuhalten, war ein Pragmatiker und kein gebildeter Mann. Er suchte stets nach einer direkten Anwendbarkeit kosmologischen Wissens. Columbus war das, was die Angloamerikaner einen self made man nennen, mit anderen Worten: er war ein Autodidakt in den Wissenschaften. Er eignete sich seine Kenntnisse selbst an, suchte sie dort, wo er sie gerade fand, und hielt vor allem nach dem Ausschau, was perfekt zu seinen Thesen passte. Dies war keine wissenschaftliche Vorgehensweise, aber doch eine sehr zielbewusste. Wir sehen folglich, dass er sich für alle unterschiedlichen Dimensionen des literarischen Reiseberichts verproviantierte.

Dabei ging alles durcheinander, und seine Informationen waren für ihn nur dann relevant, wenn sie sich mit seinen eigenen Vorstellungen verbinden ließen. So las Columbus zum einen von dem Florentiner Gelehrten Toscanelli, dass es Möglichkeiten gäbe, den Ozean auf westlichem Kurs zu durchqueren, wobei er freilich die Meilenangaben Toscanellis absenkte, um überhaupt die Chance zu haben, eine solchee Distanz überwinden zu können. Die ihm von Toscanelli übermittelte Karte mit der Angabe der dem asiatischen Kontinent vorgelagerten Vor-Inseln war von größter Bedeutung: Columbus führte sie stets mit sich mit.

Darüber hinaus berief er sich auf den Pseudo-Propheten Esdras und dessen Behauptung, die Erde bestehe zu fünf Teilen aus Land und zu einem Teil aus Wasser: Da konnte der Ozean ja nicht so groß sein! Die Einzeichnung von Vor-Inseln in die Karte Toscanellis verband er mit dem Bericht des Marco Polo vom sagenumwobenen Cipango, in dem wir das heutige Japan erkennen dürfen. Die Bezeichnung der Vor-Insel (oder auch Gegen-Insel) Antilia ging, wie Sie wissen, später auf die gesamte Region der Antillen über. Doch den Gerüchten um Vor-Inseln war nicht gänzlich zu trauen: Immer wieder gab es Berichte von sagenhaften Inseln weiter westlich im Meer - Berichte etwa von der Fahrt des Brandanus, der in Spanien San Borondón heißt, dem zu Ehren vor zwanzig Jahren eine Gesellschaft der Freunde inexistenter Inseln gegründet wurde. Eine besonders wichtige Rolle aber spielte für Columbus Pierre d'Aillys Imago 


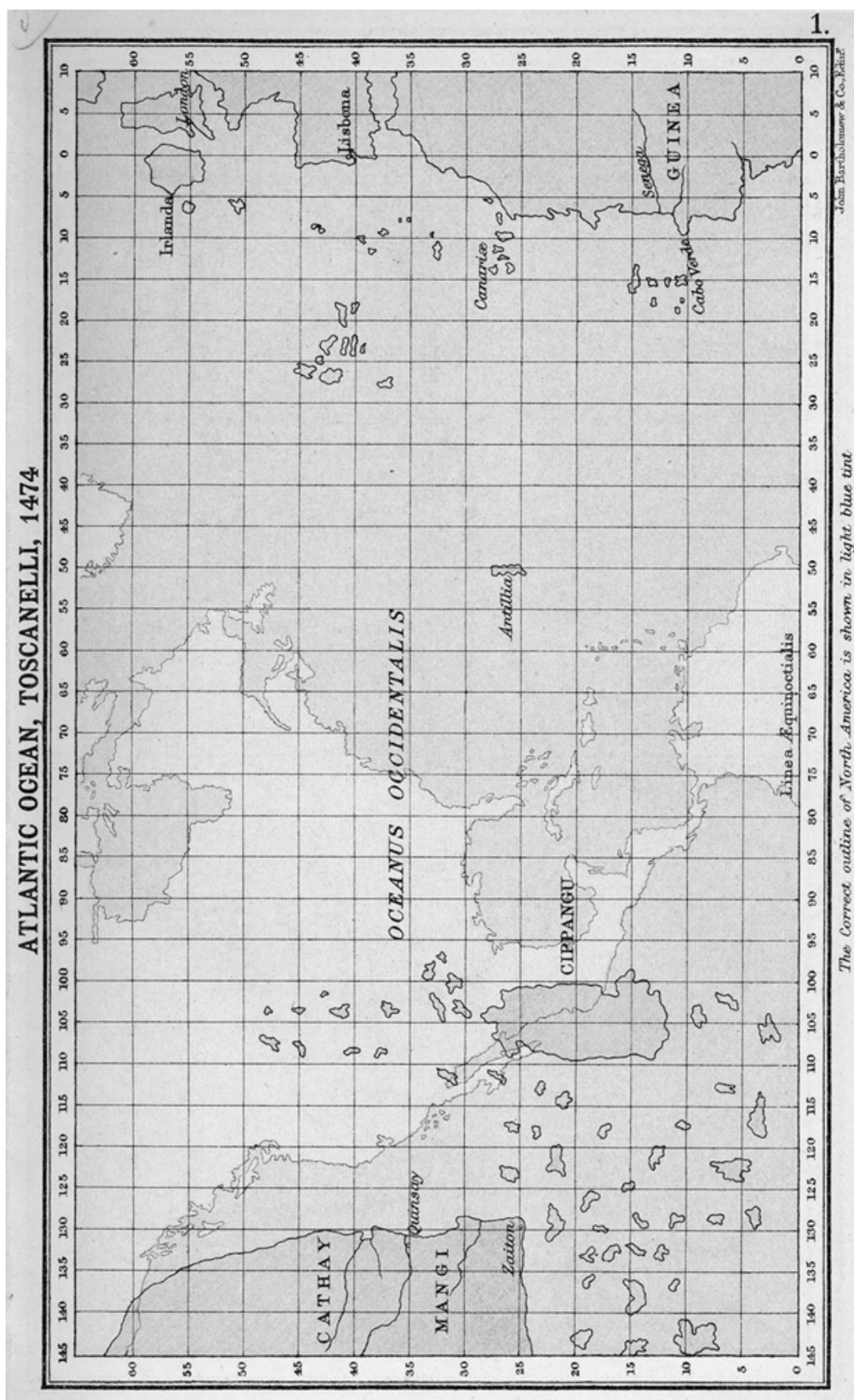

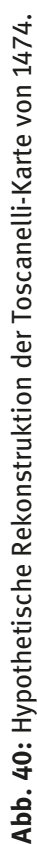


Mundi: Der kosmologischen Sammlung des französischen Kardinals entnahm er zahllose Mythen und Legenden, die gleichsam die neue, noch unentdeckte Welt vorab bereits mit ihren Vorstellungen und Gestalten bevölkerten. ${ }^{17}$ Gerade auch anhand des Bordtagebuches des Columbus wird deutlich: Die Erfindung der Neuen Welt geht ihrer Findung deutlich voraus. ${ }^{18}$ Und diese Erfindung hatte weitreichende Konsequenzen für die Eroberungs- und Kolonisierungsgeschichte des gesamten Kontinents. Columbus Diario de a bordo verkörperte die Diskurstraditionen seiner Zeit, wirkte zugleich aber durch die in seine Beschreibungen integrierten Legenden und Sagen unübersehbar diskursbildend. Der Diario enthält präzise Berechnungen und Beschreibungen, aber zugleich gefälschte Berechnungen sowie zahlreiche Mythen und Versatzstücke abendländischen Kulturkapitals, das auf die Neue Welt projiziert wurde. Wir stoßen hier massiv auf die Friktionalität der gesamten Gattung.

Eine nicht ganz unwichtige Quelle war neben Ptolemäus und den aktualisierten Karten, die der antiken Kosmologie beigegeben wurden, auch die Aufzeichnungen des Marco Polo (vgl. Abb. 14: Porträt des Marco Polo), die Columbus überaus sorgfältig las und - wie andere Werke auch, die sich in seinem Besitz befanden - mit vielen kleinen Randbemerkungen versah. All dies hat die weltweite Columbus-Forschung mittlerweile sehr sorgsam zusammengetragen. So zeigt etwa eine neuere Ausgabe von Marco Polos Bericht, ${ }^{19}$ wie vielfältig die Anmerkungen des Columbus waren, dem wir geradezu über die Schulter schauen können. Seine Randbemerkungen zeigen auch: Cristoforo Colombo war mediterran geprägt, sein Italienisch war rein mündlich und genuesisch gefärbt, sein Latein war von Lusitanismen durchdrungen, sein Kastilisch war fehlerhaft und portugiesisch, so wie sein Porgtugiesisch andalusisch war. Er war überall zuhause, zugleich überall aber auch ein Fremder: In einem ganz nietzscheanischen Sinne war er ein Europäer, ein Heimatloser.

Columbus arbeitete mit der lateinischen Ausgabe des Marco Polo, die 1485 in Antwerpen erschienen war. Der Venezianer reiste 1271, kurz zusammengefasst, über Bagdad zum Persischen Golf, von Hormus aus durch den Iran zum oberen Oxus und durch den Pamir nach Kathai, dem heutigen Nordchina, bis

17 Vgl. zu diesem Komplex Ette, Ottmar: Funktionen von Mythen und Legenden in Texten des 16. und 17. Jahrhunderts über die Neue Welt. In: Kohut, Karl (Hg.): Der eroberte Kontinent. Historische Realität, Rechtfertigung und literarische Darstellung der Kolonisation Amerikas. Frankfurt am Main: Vervuert Verlag 1991, S. 161-182.

18 Vgl. hierzu ausführlich die klassische Studie von O’Gorman, Edmundo: La invención de América. El universalismo de la cultura de Occidente. México: Fondo de Cultura Económica 1958.

19 Vgl. Gil, Juan (Hg.): El libro de Marco Polo anotado por Cristóbal Colón. El libro de Marco Polo versión de Rodrigo de Santaella. Madrid: Alianza Editorial 1987. 
hin nach Peking. Er gewann die Gunst des Mongolenherrschers und unternahm ausgedehnte Reisen durch China. 1292 kehrten die Polos zu Schiff durch das Südchinesische Meer, die Sunda-Inseln, Vorderindien nach Hormus, von hier über Iran, Armenien und Trapezunt nach Venedig zurück. In Genuesischer Gefangenschaft diktierte Marco Polo später einem französischsprachigen Mitgefangenen seinen Reisebericht, der sehr bald ins Italienische und Lateinische, später auch in andere Sprachen übersetzt wurde. Doch es geht hier nicht um Marco Polo: Lesen wir ihn vielmehr aus dem Blickwinkel des Columbus.

Um es ganz konzentriert zu sagen: Marco Polo war ein ungeheurer Antrieb für viele Europäer, sich mit den Reichtümern Indiens und Chinas zu beschäftigen; er beflügelte die Fantasien all derer, die zu diesen orientalischen Reichtümern vordringen wollten. Und Columbus notierte brav am Rande aller Texte des Venezianers Vermerke wie ‘oro en grandísima abundancia' oder auch einfach 'perlas rojas': Sie merken, der Mann war Pragmatiker und ging zur Sache.

Doch es waren keineswegs nur diese materiellen Aspekte, welche die Fantasie des Columbus erhitzten. Er las mit größter Aufmerksamkeit auch all jene Passagen nicht nur über Cipango, sondern über die gesamte Reise des Marco Polo, in denen auch die Schilderungen der Sitten und Gewohnheiten der jeweiligen Bewohner ausführlich dargestellt wurden. So finden wir etwa im 37. Kapitel des Marco Polo eine Stelle, die uns nicht unbekannt vorkommt, haben wir doch bereits derartige Hinweise bei Columbus gelesen:

Más allá del reino de Resmacoron, a cincuenta millas en alta mar, se encuentran al mediodía dos islas, distantes entre sí unas xxx millas. En una moran hombres sin mujeres, y se llama en su lengua la isla Macho; en la otra, por el contrario, habitan mujeres sin hombres, y se denomina aquella isla Hembra. Los que residen en estas islas forman una comunidad y son cristianos. Las mujeres no van nunca a la isla de los hombres, pero los hombres van a la isla de las mujeres y viven con ellas durante tres meses seguidos. Habita cada uno en su casa con su esposa, y después retorna a la isla Macho, donde permanece el resto del año. Las kujeres tienen a sus hijos varones consigo hasta los xiv años, y después los envían a sus padres. Las hembras dan de comer a la prole y tienen cuidado de algunos frutos de la isla, mientras que los hombres se proveen de alimento a sí mismos, a sus hijos y a sus mujeres. ${ }^{20}$

Sie sehen: Wir stoßen hier bei Marco Polo auf jene beiden Inseln, die Cristóbal Colón bei seiner ersten Fahrt durch die Inselwelt der Antillen bereits beschrieb, ohne doch diese beiden Inseln je besucht $\mathrm{zu}$ haben. Columbus hatte kein Verständigungsproblem: Er wollte sehen, was er zuvor als aufmerksamer Leser gelesen hatte. Oder anders: Er phantasierte die asiatische Inselwelt des Marco Polo mitten hinein in die amerikanische Inselwelt, die er durchkreuzte, ohne

20 Gil, Juan (Hg.): El libro de Marco Polo, Buch 3, Kap. 37, S. 156. 
freilich zu ahnen, dass es sich um eine den Europäern noch gänzlich unbekannte Welt handelte.

Angesichts solcher Texteffekte und Textspiegelungen erscheint es doch als reichlich einfältig, mit dem Hinweis auf derartige Beschreibungen die These halten zu wollen, dass Columbus entweder selbst schon einmal im Meer der Antillen gewesen sei oder eben sehr detaillierte Informationen erhalten habe, die ihm sofort eine Orientierung in dieser Inselwelt erlaubt hätten. Columbus war ganz einfach ein sehr aufmerksamer und zugleich pragmatischer Leser, der in der realen Welt all jenes sah, was er zuvor schon einmal gelesen hatte. Er brauchte keine zusätzlichen Informationen und Hinweise, er hatte die Welt in seinem Kopf. Auch hier geht deutlich also die Erfindung in Form der Lektüre jeglicher Findung oder Auffindung von Inselwelten voraus. Nein, er hatte es nicht nötig, diese Welt zuvor schon einmal durchsegelt zu haben: Er konnte sich wie zu Hause fühlen, denn er war in der Tat in seiner Welt. Alles war neu und alt, unbekannt und bekannt zugleich: Alles war (auf eine geradezu Freud'sche Weise) unheimlich vertraut.

Lassen Sie mich an dieser Stelle einen Auszug aus dem Beginn, dem incipit von Marco Polos Text anführen, die Columbus aufmerksam las und eigenhändig mit seinen Anmerkungen versah, welche auf uns gekommen sind. Wir sehen gleichsam dem Genuesen bei der Arbeit an den Texten des Venezianers zu und auch dies mag verdeutlichen, wie hoch gerade der Anteil der Italiener am spanischen Descubrimiento wie auch später an der spanischen Conquista ist:

\begin{abstract}
Yo, fray Francisco de Pepuris de Bolonia, de los frailes predicadores, me veo forzado por muchos padres y señores míos a trasladar la lengua vulgar al latín en verídica y fiel traducción el libro del prudente, honorable y muy fiel micer Marco Polo de Venecia sobre las costumbres y cualidades de las regiones de Oriente, publicado y escrito por él en nuestro vulgar, a fin de que tanto los que gustan más del latín que del romance como los que no pueden entender en absoluto o difícilmente las propiedad de otra lengua, por la total diferencia del idioma o por la diversidad de giros, lo lean ahora con mayor deleite o lo comprendan con más presteza. Además, los que me obligaron a tomar este trabajo no podían hacerlo del todo por sí mismos, ya que, entregados a más alta contemplación y preferiendo lo sublime a lo ínfimo, rehusaban tanto entender como escribir de cosas terrenas. En consecuencia, por acatar sus mandados, vertí el contenido de esa obra fiel e íntegramente en un latín llano y paladino, pues ese estilo requería la materia del presente libro. [...]

El primer capítulo trata de cómo y por qué motivo micer Nicolás de Venecia, padre de micer Polo, y micer Mateo pasaron a las partes de Oriente. El ii trata de cómo fueron al corte del rey máximo de los tártaros. ${ }^{21}$
\end{abstract}

Es geht hier also zjunächst einmal um die Frage der Sprache und deren Bedeutung. Deutlich wird in diesen Überlegungen zu Beginn der Lektüre die

21 Gil, Juan (Hg.): El libro de Marco Polo, S. 11 ff. 
entscheidende Bedeutsamkeit der Übersetzung für diesen Reisebericht des Marco Polo wie auch für alle Reiseberichte, mit denen wir uns beschäftigen. Denn das Sprechen, das Schreiben über eine andere Welt beinhaltet stets eine Frage nach dem Übersetzen, so wie andererseits der Reisebericht auch immer die Frage nach der adäquaten Sprache für eine Leserschaft aufwirft, die über diese andere Welt ins Bild gesetzt werden will. Die Übersetzungsdimension ist, auch wenn ich sie in der Vorlesung nicht überall ansprechen kann, doch von höchster Wichtigkeit, macht sie doch die doppelte Bewegung des Übersetzens und des Über-Setzens sehr klar und deutlich, wobei die abschließenden Sätze des oben zitierten Teiles dann schon den Übergang zum Inhaltsverzeichnis des Reiseberichts darstellen. Aber wir sollten uns stets vor Augen halten, dass jeder Reisebericht an sich die Bewegungen der Übersetzung und des Übersetzens in sich aufnimmt, dass also die Wahl der Sprache - dies kann auf der Ebene der Stilistik auch eine intralinguale Entscheidung über ein Sprachregister sein - viel über den Reisebericht selbst aussagt. Nein, es war keineswegs gleichgültig, dass sich der Preuße Alexander von Humboldt in seiner Relation historique für das Französische entschied und später enorme Probleme mit den deutschsprachigen Ausgaben auftraten.

Die vielen Reiseberichte und impliziten oder expliziten Intertexte, aber auch die Mythen und Legenden, die sich um Länder und Inseln im Westen, gleichsam über den weiten, nur scheinbar unbeschriebenen Flächen des Meeres, gesponnen hatten, waren wichtige Teile ihm Gewebe, waren Columbus gewobener Text genug, in dem er sich sicher bewegen konnte. Der künftige Admiral verkörperte für sich selbst bereits die Figur des Entdeckers, die sich in dem bereits von Europa aus erfundenen Welten geradezu traumwandlerisch bewegte. Wie hätte er auch nur daran zweifeln können, dass dies keine unbekannten Lande, sondern ganz sicher und gewiss die Gestade des asiatischen Kontinents sein mussten. So konnte Columbus nicht verstehen, dass er in einer weiteren, in einer 'neuen' Welt angekommen war: $\mathrm{Zu}$ sicher hielt ihn die alte im Griff. Und selbst wenn es diese Welt nie gegeben hätte: die Europäer hatten deren Baupläne doch schon längst entwickelt und konkret in ihre Konstruktionszeichnungen übertragen. Es gab die Insel der Männer, es gab die Insel der Frauen, alles hatte seinen Platz und seine Berechtigung.

Christophorus Columbus steckte aber - und dies ist seine andere Seite, sein zweites Gesicht - nicht nur voller Zeichen und Symbole, Legenden und Vorstellungen, die alle europäischen Völker zum damaligen Zeitpunkt miteinander verbanden, sondern war - und auch dies ist durchaus ein europäischer Charakterzug - voller Konzepte und Konzeptionen recht präziser Art bezüglich der pekuniären Rentabilität seines Unterfangens. Die Unternehmung des Columbus 
war in diesem Sinne das Vorhaben eines Unternehmers. Der Genuese war auch ein kühler Rechner.

Gewiss: Vor Expertenkommissionen konnte Columbus nie bestehen, da sein Wissen nicht mit dem wissenschaftlichen Wissen seiner Zeit direkt kompatibel war und er auf unterschiedlichste Quellen und Vorstellungen rekurrierte und diese miteinander mischte. Das hat die Wissenschaft noch nie gerne gesehen. Für sein Vorhaben selbst mochte dies von Vorteil gewesen sein, nicht aber für die erläuternde Darstellung desselben.

Machen wir uns nochmals kurz die globalhistorische und machtpolitische Situation klar. In jenen Jahren entschied sich der portugiesische Königshof, trotz mancher Vorschläge etwa auch von Seiten Toscanellis, einen Westweg zu erkunden, klar für die afrikanische Route, also für den Ausbau der Wege und Stützpunkte von Kap zu Kap entlang der afrikanischen Küste. Die Portugiesen hatten hier seit den Zeiten Heinrich des Seefahrers einen technologischen, nautischen und kartographischen Vorsprung erreicht, der von den anderen Schifffahrtsnationen Europas nicht leicht aufgeholt werden konnte. Um 1485 gab Columbus sein Unterfangen in Portugal auf.

Es folgten sieben lange Jahre des Versuches, die spanischen Machthaber, die späteren Katholischen Könige, zu gewinnen. Diese waren auf dem Weg zu ihrer historischen Rolle und Berühmtheit und mussten dafür zunächst die inneren Zwistigkeiten, den Bürgerkrieg in Kastilien um die Thronfolge, die endlosen Streitigkeiten mit Portugal und vieles mehr lösen, um einen möglichst einheitlichen Staat zu schaffen. Und die Reconquista war keineswegs gesichert. In ihre Zeit fällt die Einführung der Inquisition, welche die Kirche zu einer Partnerin der unmittelbaren politischen Macht machte; in ihre Zeit fällt aber auch eine enorme Straffung und Modernisierung des Staatswesens in Spanien, das zu einem modernen Staat aufstieg. Der moderne, im Grunde neuzeitliche Staat begann zu entstehen.

Columbus mühte sich redlich, aber vergeblich, die wissenschaftlichen Kommissionen davon zu überzeugen, dass sein Weg erfolgversprechend sein konnte. Schließlich schreckten auch seine enormen Forderungen ab, Forderungen, die er als Entdecker von Gebieten dann gegenüber den Katholischen Königen einklagen konnte. Wie auch immer: Wir nähern uns dem jahr der Wunder, dem annus mirabilis 1492, in dem schließlich die Reconquista durch die Vertreibung der Nasriden aus Granada abgeschlossen wurde, in dem - das war schon kein Wunder mehr die religiöse Einheit des Staates beschlossen und zugleich die Juden, die nicht zum rechten Glauben übertreten wollten, aus Spanien vertrieben wurden. Es war ein Jahr, in dem darüber hinaus auch die Durchsetzung des Kastilischen durch die berühmte Grammatik des Nebrija - Siempre la lengua fue compañera del Imperio - vorbereitet wurde, eine sprachliche Expansion, die man auch als Globalisierung der kastilischen Sprache beschreiben kann. Ja, und 
dann gab es ja noch immer diesen Ausländer, der auf keinen Fall seine Herkunft verraten wollte, der aber sehr wohl wusste, wohin er wollte: Colombo alias Colón alias Columbus.

Nun, ich erzähle Ihnen die mit vielen Details ausgeschmückte Geschichte der vielen Neins, der dramatischen Abreise des enttäuschten und verletzten Colombo vom Hofe in Santa Fe - noch war Granada nicht gefallen - und sein märchenhaft anmutendes Zurückholen lieber nicht. Entscheidend aber für uns ist, dass am 17. April 1492 die Capitulaciones de Santa Fe geschlossen wurden, der erste Vertrag zwischen Europäern wohlgemerkt über die Aufteilung der erst noch zu entdeckenden Welt. Bereits in der Präambel gibt es eine Reihe von Hinweisen, wie sich Columbus diesen Vertrag vorgestellt und schließlich auch durchgesetzt hatte. Er war in der Tat ein kühler Rechner, der wusste, was seine Idee wert war. Es ist eine wahre Aufteilung der Welt, die den neuen Admiral, als den sich Columbus schon sah, auf einen Schlag zu einem Edelmann und einen der reichsten Männer seiner Zeit machen würde, sollte das Unternehmen gelingen. Und gelingen hieß in jedem Falle, erfolgreich nach Europa zurückzukehren, die koloniale Kreisfigur zu schließen. So lesen wir in der Präambel:

Vuestras Altezas dan e otorgan a don Christóbal de Colón en alguna satisfación de lo que ha descubierto en las Mares Océanas y del viage que agora con el ayuda de Dios ha de fazer por ellas en servicio de Vuestras Altezas. ${ }^{22}$

Am Anfang wie am Ende stehen die Königlichen Herrschaften, im Zentrum aber Columbus selbst. Allerdings wissen wir: Am Ende der Geschichte werden die Katholischen Könige das letzte Wort haben und den aufmüpfigen Ausländer zur Räson (und zur Verzweiflung) bringen. Interessant ist hier die Formulierung, die schon Las Casas für einen Lapsus hielt, dass hier von den Ländern die Rede ist, die Columbus bereits im Ozean entdeckt habe. Das gab tatsächlich Anlass zu dem Verdacht, dass der findige Genuese schon einmal die antillanische Inselwelt inspiziert hatte und nun deren Besitz sich erst einmal sichern wollte.

Wenig wahrscheinlich ist, dass dem tatsächlich so war. Columbus sicherte sich vielmehr argumentativ ab gegen jedweden anderen Versuch, Ansprüche auf diese Inseln und Länder anzumelden: Denn der Vertrag spricht stets von Inseln und von Festländern im Plural, also deutlich von sehr unterschiedlichen Gebieten, aber wohl nicht aus Kenntnis der Lage des Kontinents - dies bemerkt man auch bei den späteren Reisen, dass hier keine konkreten Ortskenntnisse vorlagen -, sondern um diskursiv allen Eventualitäten und Rechtsansprüchen vorzubeugen.

22 Colón, Christóbal: Capitulaciones del almirante Don Cristóbal Colón y salvoconductos para el descubrimiento del Nuevo Mundo. Madrid: Ministerio de Edcuación, Cultura y Deporte 2013, S. 21. 
Sollte das Unternehmen gelingen, so sicherte sich Columbus den im Übrigen vererbbaren Titel und Rang eines Admirals des Ozeanischen Meeres, wurde zugleich zum Vizekönig und zum Gouverneur der neu entdeckten Gebiete und konnte hier die eigentlichen Strukturen einschließlich der Rechtsprechung aufbauen. Er erreichte - dies allerdings nicht in der Form eines Vertrags, sondern einer königlichen Merced, die dann auch später zurückgezogen wurde -, dass auch seine Titel als Vizekönig und Gobernador vererbbar wurden. Zugleich sollte ihm ein Zehntel aller Einkünfte gehören, die als Gewinn nach Spanien an die Könige transferiert würden, und es stand ihm auch frei, an allen Expeditionen ein Achtel der Kosten zu tragen, um dann später auch ein Achtel aller Gewinne einstreichen zu können. Fürwahr: Fürstliche Bedingungen für einen hartnäckigen, klugen Seefahrer aus letztlich einfachen Verhältnissen.

Wie wir bereits erwähnten, verlief lange Zeit auf spanischen Karten der Nullmeridian durch die Insel Hierro, sozusagen das Greenwich Spaniens. Von hier aus wurden die europäischen Kartennetze über die Welt ausgeworfen, in denen sich die von den Europäern neu entdeckten Inseln und Festländer verfingen. Von hier aus wurden aber auch all jene Träume von Inseln und Kontinenten weiter nach Westen projiziert, von denen wir schon gehört hatten. Columbus war mit all diesen Erzählungen, Geschichten und Legenden bestens vertraut. Er zeigte in seiner Eintragung im Bordbuch vom 9. August nicht nur seine Vertrautheit mit all diesen Narrativen; auch erweist sich hier, wie wichtig es für ihn war, in Portugal Informationen gesammelt und auch selbst eine Zeit lang auf Porto Santo gelebt und die Azoren besucht zu haben. Dabei ist er sich seines eigenen Zieles gewiss:

Dice el Almirante que juraban muchos hombres honrados españoles que en la Gomera estaban con doña Inés Peraza [. . .], que eran vecinos de la isla de Hierro, que cada año veían tierra al oeste de las Canarias, que es al Poniente, y otros de la Gomera afirmaban otro tanto con juramento. dice aquí el Almirante que se acuerda que estando en Portugal el año de 1484 vino uno de la isla de la Madera al rey a le pedir una carabela para ir a esta tierra que veía, el cual juraba que cada año la veía y siempre de una manera. Y también dice que se acuerda que lo mismo decían en las islas de los Azores [. . .]. Finalmente se hizo a la vela de la dicha isla de la Gomera con sus tres carabelas, jueves a seis días de septiembre. ${ }^{23}$

Christoph Columbus glaubt nicht an derartige aus dem Meer auftauchende Inseln. Er lässt sich also nicht beirren, weiß sehr wohl um diese mythischen Inseln, die immer wieder im Meer verschwinden. Und er weiß, daß er eine sehr lange Seereise vor sich hat. In seinem Ausgangsbefehl an die Kapitäne der beiden anderen Schiffe hatte er bereits darauf aufmerksam gemacht, dass man

23 Colón, Cristóbal: Diario de a bordo, S. 75: 
erst nach etwa 700 Meilen aufpassen müsse, die Inseln, Cipango, nicht zu verpassen, da ansonsten der Weg zum asiatischen Festland $\mathrm{zu}$ weit sein könnte und die Lebensmittel nicht für eine derart lange Überfahrt reichen würden. Man kann erkennen, welch hohe strategische Bedeutung die Karte des Toscanelli für den Genuesen besaß: Sie bot ihm Sicherheit.

Ab dieser Entfernung durfte dann auch nachts nicht mehr gesegelt werden, um nicht in der Dunkelheit an den Inseln vorbeizusegeln. Da Columbus aber wusste, wie weit diese Reise sein würde, tat er etwas, das er schon in seiner Zeit als Kapitän eines Korsarenschiffes immer wieder getan hatte: Er führte seine Leute, seine Matrosen, hinters Licht. Denn ab diesem Zeitpunkt begann er, nicht mehr die tatsächlich zurückgelegte Distanz anzugeben, sondern schwindelte immer einen beträchtlichen Teil weg, so dass es schien, als komme man langsamer nach Westen vorwärts. Dieses Verfahren war sicherlich erfolgreich, konnte ihn aber nicht davor bewahren, dass nach etwa dreißig Tagen der Seefahrt westwärts - wie wir bereits sahen - die Geduld der Männer erschöpft und die Ängste gewachsen waren, nicht mehr wieder nach Spanien zurückkehren zu können. Man wusste an Bord nur zu genau, dass der point of no return erreicht war. Aber Columbus blieb stur und seiner Idee treu.

Gegen Abend des 11. Oktober nun sahen die Männer tatsächlich Land, nachdem sie bereits Wochen zuvor einmal fälschlich geglaubt hatten, auf eine Insel gestoßen zu sein. Die Schiffe segelten daraufhin vorsichtig in die Dämmerung und Nacht hinein, bis man tatsächlich in der unmittelbaren Nähe von Land war. Diese für die weitere Geschichte Amerikas, aber auch Europas höchst wichtige Passage möchte ich Ihnen gerne vorführen, zeigt sie doch eine Verhaltensweise, mit der wir auch heute noch sehr vertraut sind:

A las dos horas después de media noche pareció la tierra, de la cual estarían dos leguas. Amaynaron todas las velas, y quedaron con el treo, que es la vela grande, sin bonetas, y pusiéronse a la corda, temporizando hasta el día viernes que llegaron a una isleta de los Lucayos, que se llamaba en lengua de Indios Guanahani. Luego vieron gente desnuda, y el Almirante salió a tierra en la barca armada y Martín Alonso Pinzón y Vicente Yáñez, su hermano, que era capitán de la Niña. Sacó el Almirante la bandera real, y los capitanes con dos banderas de la cruz verde, que llevaba el Almirante en todos los navíos por seña, con una $\mathrm{F}$ y una $\mathrm{Y}$, encima de cada letra su corona, una de un cabo de la + y otra de otro. Puesto en tierra vieron árboles muy verdes, y aguas muchas y frutas de diversas maneras. El Almirante llamó a los dos capitanes y a los demás que saltaron en tierra, y a Rodrigo de Escobedo, escribano de toda la armada, y a Rodrigo Sánchez de Segovia, y dijo que le diesen por fe y testimonio como él por ante todos tomaba, como de hecho tomó, posesión de la dicha Isla por el Rey y por la Reina sus señores haciendo las protestaciones que se requerían, como más largo se contiene en los testimonios que allí se hicieron por escrito. Luego se junto allí mucha gente de la Isla. Esto que se sigue son palabras formales del Almirante en su libro de su primera navegación y descubrimiento de estas Indias: 'Yo, dice él, porque 
nos tuviesen mucha amistad, porque conocí que era gente que mejor se libraría y convertiría a Nuestra Santa Fe con amor que no por fuerza, les di a algunos de ellos unos bonetes colorados y unas cuentas de vidrio que se ponían al pescuezo, y otras cosas muchas de poco valor, con que hubieron mucho placer y quedaron tanto nuestros que era maravilla. Los cuales después venían a las barcas de los navios a donde nos estábamos, nadando y nos traían papagayos y hilo de algodón en ovillos y azagayas y otras cosas muchas, y nos las trocaban por otras cosas que nos les dábamos, como cuenticillas de vidrio y cascabeles. [.. .] Ellos no traen armas ni las conocen, porque les mostré espadas y las tomaban por el filo, y se cortaban con ignorancia. No tienen algún hierro [...]. Yo placiendo a Nuestro Señor, llevaré de aquí al tiempo de mi partida seis a Vuestra Alteza para que aprendan a hablar. Ninguna bestia de ninguna manera vi, salvo papagayos en esta Isla.' Todas son palabras del Almirante. ${ }^{24}$

Diese Passage ist in vielerlei Hinsicht bemerkenswert. Denn diese Szene einer ersten offiziellen Inbesitznahme amerikanischen, wenn Sie so wollen indianischen Landes vollzieht sich nach allen Regeln europäischer Kunst und europäischen Rechts. Colón macht hier seinem Namen alle Ehre: Er kolonisiert das Land mitsamt seiner Bewohner. Doch wie geht er vor?

Nach einer ausgetüftelten europäischen Rechtsvorschrift. Denn was hier geschieht, ist die Praxis des requerimiento, der Inbesitznahme, die nach ganz bestimmten juristischen Formen abzulaufen hatte. Zum einen werden die Fahne und die Insignien der Katholischen Könige entfaltet als Zeichen dafür, dass nicht etwa für einen Privatmann oder eine Gruppe von Abenteurern, sondern für eine legitime Monarchie und einen neuzeitlichen Staat territoriale Ansprüche geltend gemacht werden. Die dem kuriosen Treiben der Europäer zweifellos verwundert zuschauenden eigentlichen Bewohner und Besitzer des Landes werden nicht als Rechtssubjekte anerkannt. Die Spanier bleiben in der recht farbenprächtigen und hochoffiziellen Szenerie des requerimiento unter sich: Eine Beteiligung der indigenen Bevölkerung ist nicht vorgesehen, ihnen kommt keinerlei agency zu.

Die Inbesitznahme eines Territoriums direkt vor den Augen der eigentlichen Besitzer? Dies ist von juristischer Seite vor dem Hintergrund der europäischen Rechtsauffassungen der Zeit durchaus legitim. Denn die Indianer sind, ebenso wie die Afrikaner in Afrika, keine Rechtssubjekte in vollem Sinne: Über sie kann ohne vorherige Konsultation mit ihnen befunden und verfügt werden.

Die Voraussetzungen für derartige Inbesitznahmen waren längst eingespielte juristische Verfahren, wie sie die Portugiesen etwa seit Jahrzehnten praktizierten: Schriftführer und Zeugen dienten der Beglaubigung, eine Unterschrift etwa von Eingeborenen war nicht vorgesehen. Die Europäer setzten ihr eigenes Völkerrecht, bei dem freilich die Spielregeln eingehalten werden müssen. So müssen

24 Ebda., S. 89. 
etwa die Fahne entrollt und aufgezogen werden, bestimmte juristisch bindende Formeln sind zu sprechen, der ganze Vorgang muß bezeugt und besiegelt sein, die Erde, um die es geht, muß berührt worden sein, damit ihre Inbesitznahme auch rechtens und verbrieft ist. Allesamt Rechtshandlungen, die allein von Europäern auszuführen sind. Ruckzuck ist alles fertig.

Dann wird der Vorgang protokolliert und von den Anwesenden als rechtmäßig festgestellt und unterschrieben. Dadurch geht ein Rechtstitel über in den Territorialanspruch des betreffenden Monarchen, hier der Katholischen Könige, deren Königreich diese Länder einverleibt werden. Juristisch ergibt sich daraus, dass es wiederum die Katholischen Könige sind, welche dann die weiteren Rechte ihrerseits an Columbus vergeben.

Was wir hier vor uns haben, ist also die erste Umsetzung der Bestimmungen und Vereinbarungen zwischen den beiden europäischen Vertragspartnern, den Katholischen Königen und Columbus; der zweite Schritt, nämlich die Verleihung der territorialen, administrativen und juristischen Rechte einschließlich des Rechts der Vererbung, erfolgt dann durch die Legitimation von Seiten der Katholischen Könige, ganz im Sinne der Capitulaciones de Santa Fé. Dazu muß die Rückkehr des Columbus nach Spanien erfolgen: Erst dann kann er wieder in die Neue Welt absegeln, die nun in gewisser Weise zu seiner eigenen Welt geworden ist.

Für die zufällig anwesenden Bevölkerungsgruppen des zu den Taínos gehörenden lucayanischen Volkes muß dieses Schauspiel vielleicht so gewirkt haben wie umgekehrt ein indianischer Ritus eines Schamanen, der etwa auf der Terrasse von Sanssouci vollzogen wird, auf die Europäer von Potsdam wirken würde: recht hübsch und bunt, aber letztlich nicht nachvollziehbar. Wir haben es hier im Sinne von Urs Bitterli ${ }^{25}$ mit einer Kulturberührung zu tun: Es ist noch kein Kulturkontakt, der das Fremde direkt aufeinanderprallen lässt, ohne dass es doch zur offenen Konfrontation, zum direkten Konflikt, zum Kampfe käme. Friedlich - und ohne Wissen der Bevölkerung - ist indianisches Land in den Besitz Spaniens übergegangen und wird wiederum von den Herrschern Spaniens zur weiteren Kolonisierung an den Genovesen Columbus übergeben. Dieses Modell sorgt im Grunde für einen geradezu direkten Übergang der Reconquista in die Conquista wie weiter in die Colonia. Spanien befindet sich in einer fast ununterbrochenen Expansionsbewegung, die nun nach Übersee ausgreift.

Wäre die 'Entdeckung' Amerikas nicht unmittelbar nach der Eroberung des letzten Maurenreiches von Granada gekommen, dann wäre die Reconquista vermutlich auch so in eine Conquista übergegangen, nur dass in diesem Falle sicherlich

25 Vgl. Bitterli, Urs: Die 'Wilden' und die 'Zivilisierten'. Die europäisch-überseeische Begegnung. München: Deutscher Taschenbuch Verlag 1982. 
Nordafrika zur bevorzugten Beute des spanischen beziehungsweise kastilischen Expansionismus geworden wäre. So aber begann der amerikanische Traum, die ilusión indiana, konkrete Gestalt anzunehmen und die spanische Soldateska, die nach dem Fall von Granada zu hochgerüstet war, auf den Plan zu rufen. All dies ist ebenfalls in dieser Szene auf den heutigen Bermudas präsent.

Aufschlussreich ist, dass auf den konkreten Akt der Inbesitznahme im Reisebericht des Colón ein geradezu literarisches Versatzstück folgt. Die Beschreibung der nun in Besitz genommenen Insel folgt den Regeln nun nicht mehr des europäischen Rechts, sondern der europäischen Literatur. Denn es folgt sogleich die Beschreibung eines locus amoenus, eines Lustortes, wo es weder an grünen Bäumen noch an freundlichen Wiesen noch an Früchten mancherlei Art noch an Flüsschen oder Bächen fehlen darf. All diese Elemente werden im Diario de a bordo in der Transkription von Fray Bartolomé de las Casas nach bester abendländischer Tradition nachgeliefert. Der konkrete Ort der Bahamas oder der Antillen hätte im Grunde überall sein können: Er ist bevölkert von europäischen Versatzstücken, wird einbezogen in eine abendländisch-europäische Welt, die ihre Konzepte und Konzeptionen wie die Netze ihrer Kartenwerke sukzessive über die gesamte Erde auszubreiten beginnt.

Danach lässt Las Casas den Protagonisten, die Hauptfigur der ganzen Ereignisse, in seinem Excerpt selbst zu Wort kommen. Wenn man schematisch die Transkription von Las Casas in die drei genannten diskursiven Bestandteile also die Transkritpion in indirekter Rede, den Kommentar und das direkte, unmittelbare Zitat - unterscheidet, so wird deutlich, dass der Dominikaner an den entscheidenden Stellen Columbus selbst zu Wort kommen lässt. Hier nun kommt es zu einem ersten Austausch nicht zwischen Europäern, sondern zwischen den Europäern und jenen Bewohnern, die bislang allein Gehandelte, Fremdbestimmte waren.

Nun, sie werden es auch bleiben, werden zugleich aber in die Rolle von Tauschenden, also gleichsam einen Vertrag über Tauschhandel oder über den wechselseitigen Austausch von Gütern Abschließenden gedrängt. Die terms of trade werden freilich von den Europäern, den Spaniern bestimmt. Denn die Spanier hatten billige Tauschgüter, Glasperlen etwa und kleine Schellen, just für diesen Zweck mit an Bord genommen. All dies steht für den künftigen Admiral der Ozeanischen Meere im Zeichen des Wunderbaren: Er vermeint offensichtlich, zwar nicht den Atem der Geschichte - das konnte er noch nicht, denn die Geschichte als Kollektivsingular war noch nicht erfunden -, wohl aber die Hand Gottes zu spüren, die ihm half.

Der Dominikaner hebt just diesen Aspekt hervor, indem er darauf verweist, wie Columbus nun offensichtlich diese Indianer - wie wir sie nun auch nennen wollen - als künftige Christen sieht, die leicht zum wahren Glauben zu bekehren 
seien. Hier wiederum macht Christophorus, der Christusträger oder Christusbringer, seinem Vornamen alle Ehre. Er hat diese Menschen noch kaum gesehen, und doch weiß er schon, dass man zu ihrer Bekehrung zum Heiligen Glauben, die selbstverständlich als solche außer Frage steht, keine Gewalt und keinen Zwang werde anwenden müssen. Die Indianer scheinen in ihrer Unschuld wie unmündige Kinder geradezu auf ihren Erlöser, auf Columbus, die Taube, auf den Christum ferens, den Gottes-Träger, gewartet zu haben. Hier tritt ein weiteres und ganz spezifisches Deutungsmuster und Selbstdeutungsmuster des Cristoforo Colombo hervor: Er ist sich seiner Sache sicher, denn er weiß um seinen Namen und weiß um seinen göttlichen Auftrag. Letztlich wird er die drei Bestandteile seines Namens seiner eigenen, aber gleichsam göttlich legitimierten Deutung unterwerfen: Er ist der Gottesbringer, die Friedenstaube und der Kolonisator in einem. Seltsam, wie an diesem Übergang zwischen Mittelalter und Renaissance - und ganz im Sinne Michel Foucaults ${ }^{26}$ - die Welt noch einmal geradezu durchsichtig, in ihrem Sinn und in ihren Bedeutungen transparent zu werden scheint.

Jenseits dieses Sendungsbewusstseins findet auf den Inseln mit der lucayanischen Bevölkerung ein simpler trueque, also ein Warentausch statt, der ohne Geld als vermittelndem Medium auskommt. Dafür verwendet Columbus völlig korrekt den Fachbegriff des trocar: Auch in diesen Dingen war er kaufmännisch erfahren und hatte für diese Situation vorgesorgt.

Allerdings werden noch nicht jene Güter sichtbar, an denen die Europäer zuallererst interessiert sind: Gold und Silber, Gewürze und Spezereien. Glasperlen und billigen Tand hatten die Portugiesen aber bereits erfolgreich in Afrika in ihren Faktoreien und Handelsstützpunkten eingesetzt. Die Billigprodukte aus Europa werden eingetauscht gegen Papageien, gegen Baumwolle, die Columbus ebenfalls bekannt ist, so dass es eigentlich noch nicht zu einem Tausch von Waren, sondern zu einem symbolischen Bündnis mit den Taínos kommt. Dass dabei wieder Vögel im Spiel sind, mag vielleicht nur Papageienliebhabern auffallen. Doch in Wirklichkeit haben wir es mit einer ungeheuer spannenden Sache zu tun: dem symbolischen Beginn des Kolonialsystems.

Columbus beruhigt zugleich offenkundig seine Auftraggeber, dass es hierbei nichts zu befürchten gebe, verfügten die Indianer doch nicht über Waffen, welche die Europäer ernsthaft gefährden könnten. Ganz im Gegenteil: Die Indios kennen noch nicht einmal die Waffen der Europäer, schneiden sich ungeschickt an den gehärteten Klingen ihrer Schwerter. Was für ein Machtgefühl muss dies für die Europäer gewesen sein! Doch dieses Machtgefühl kippt sofort in ein Machtkalkül,

26 Vgl. Foucault, Michel: Les mots et les choses. Paris: Gallimard 1966; dt. Die Ordnung der Dinge. Eine Archäologie der Humanwissenschaften. Frankfurt am Main: Suhrkamp 1974. 
wird zur kühlen Berechnung dessen, was aus diesen Menschen, aus diesen Kolonien herauszuholen sein wird. Der Nützlichkeitsgedanke, ja mehr noch der Gedanke der Ausbeutung durchdringt das gesamte Denken des Cristóbal Colón.

Deutlich ist auch, dass einige Exemplare dieser Gattung mitgenommen werden sollen, damit sie sprechen lernten. Als ob sie nicht sprächen. Sprechen scheint nur eine Sache der Europäer zu sein, die sich in europäischen Sprachen verständigen. Wir stoßen hier auf den ur-abendländischen Ursprung der griechischen Rede von den 'Barbaren', die nur ein unverständliches 'baba' hervorbrächten und mithin durch ihre Sprache disqualifiziert seien. Den Europäern unverständliche Sprachen werden kurzerhand als Sprachen nicht anerkannt. Das Kriterium der Sprache stellt von Beginn an ein wichtiges Kriterium für Zivilisation dar, von der man die 'Wilden' abgrenzt. Noch wichtiger sollte in der Folge das Kriterium der Schrift und zwar allein der abendländischen Alphabetschrift - werden, um die 'Wilden' und 'Barbaren' von den 'Zivilisierten' zu unterscheiden.

Von einer schriftlosen Welt grenzt sich die beglaubigte und verschriftlichte Kultur der Rechtsgelehrten und der Escribanos, der Schreiber, deutlich ab, wie auch im Akt des requerimiento deutlich wurde. Für lange Jahrhunderte sollten in den Amerikas so die indigenen Bevölkerungen und die Bevölkerungen auf dem Land von der Ciudad letrada, ${ }^{27}$ von der Stadt der Schriftkundigen, unterschieden und abgetrennt werden, wobei in letzterer allein Recht, Macht und Gewalt lag. Selbst die Schriftsysteme der indigenen Hochkulturen in den Amerikas bildeten hier keine Besonderheit, wurden sie doch in einen marginalen gesellschaftlichen Raum abgedrängt und zählten letztlich nicht als Schriftsysteme, die mit den aus Europa importierten hätten mithalten können. Die abendländische Alphabetschrift allein garantierte den Zugang zur Macht. Dies wurde von Beginn an in der allerersten Szene der Inbesitznahme auf Guanahani deutlich. Hier wurde der Diario de a bordo gleichsam zum Seismographen dieser Entwicklung und zugleich zu seinem besten Propagandainstrument.

Ein weiteres Zeichen von Zivilisation und Kultur ist für Columbus die Verfügbarkeit von Tieren, also deren Nutzbarmachung als Haustiere auf einer für ihn höheren Zivilisationsstufe. Es geht also um direkte Zeichen von Ackerbau und Viehzucht, also letztlich um die Kategorisierung in einer Kulturstufe, der man die Indianer zuweisen kann: Handelt es sich um Nomaden oder um sesshafte Völker, handelt es sich um Ackerbauern oder um Viehzüchter, gibt es Haustiere, die sie sich gefügig gemacht haben und deren Arbeitskraft sie nutzen? All dies sind wichtige Fragen, die Columbus hier mit einem durchaus scharfen Blick sofort abruft und in seiner eigenen Schrift festhält. Der Diario de

27 Vgl. Rama, Angel: La ciudad letrada. Hanover: Ediciones del Norte 1984. 
a bordo, ein eigentliches Schiffstagebuch, wird hier zum ethnographischen Forschungsinstrument, das die Feldforschung des Ethnographen und Völkerkundlers unmittelbar formuliert und festhält.

Christoph Columbus war erfahren in diesen Dingen, hatte in Portugal und auf seinen Fahrten zwischen Island und der afrikanischen Westküste sicherlich viel gelernt. Aber es erstaunt doch, mit welcher Sicherheit und Schnelligkeit er mit einem raschen Blick auf ganze Völkerschaften deren Kulturstufe zu kategorisieren scheint und einordnen zu können glaubt. Eines jedenfalls ist sicher: Die Papageien zählen für ihn nicht, denn es sind keine Haustiere in jenem wirtschaftlich relevanten Sinne, der den Genuesen interessiert. Und es ist ein interessierter Blick, der hier auf die Taínos geworfen wird, ein Blick, der nach ihrer Verwendbarkeit als Sklaven fragt und auch nach ihrer Bereitschaft, sich zum Christentum bekehren zu lassen.

So zeigt uns eine aufmerksame Lektüre des Bordbuches des Columbus, dass in eben jenem Augenblick der ersten Landung und sofortigen Inbesitznahme im Grunde eine lange Geschichte der europäischen Kolonisierung aufscheint, fragten sich doch noch im 19. Jahrhundert etwa die deutschen Reisenden Spix und Martius in Brasilien nach den jeweiligen Kulturstufen der Amazonasindianer, bezweifelten im Grunde ihre Zurechnung zur Menschheit und diskutierten ihre Verwertbarkeit innerhalb eines von ihnen offen unterstützten Systems der Sklaverei und Plantagenwirtschaft. Sicherlich schrieb sich der Diskurs des Columbus ein in die Diskurse seiner Zeit: Er hatte zweifellos dies alles nicht erfunden. Und doch verblüfft, wie dicht seine Lektüre an diesen Stellen ist, an dem ihm Las Casas das direkte Wort lässt, und wie sehr es vorwegnimmt, was jahrhundertelang gängige europäische Praxis war.

Nun kann man zweifellos behaupten, dass die Lektüre des Bordbuches von Columbus eine Sache vor 1982 war und eine andere nach jener so wichtigen kritischen Lektüre durch den bulgarischen Strukturalisten Tzvetan Todorov, der zu jenem Zeitpunkt bereits einer der großen Vertreter französischen Denkens in der Welt geworden war. Tzvetan Todorov, keineswegs ein Lateinamerika-Spezialist (was man ab und an bemerkt), interessierte sich für die Geschichte der Eroberung als Geschichte der Auseinandersetzung mit kultureller Alterität. Und er hat sich gerade die Vorstellungen und die Texte des Columbus vorgenommen, um daraus allgemeinere Einsichten ableiten zu können über den Umgang der Europäer mit den Nicht-Europäern und über die dominanten Diskursstrategien, die dabei wirksam wurden (und werden).

Ich möchte Ihnen an dieser Stelle gerne einen Auszug aus seinem Buch Die Eroberung Amerikas vorstellen, der für unsere Vorlesung insgesamt von Interesse und Bedeutung ist. Es geht um Columbus und dessen Verhältnis zu den Indianern: 


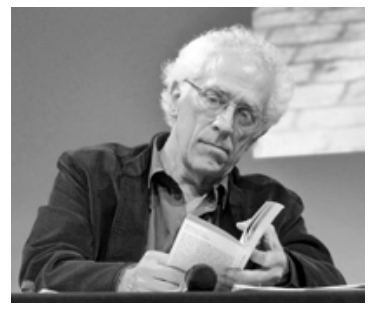

Abb. 41: Tzvetan Todorov (Sofia, 1939 - Paris, 2017).

\begin{abstract}
Entweder sieht er die Indianer (ohne sich jedoch dieser Begriffe zu bedienen) als vollwertige Menschen, die dieselben Rechte besitzen wie er, betrachtet sie dann jedoch nicht nur als gleich, sondern auch als identisch, nimmt also eine Haltung ein, die zum Assimilationismus, zur Projektion eigener Werte auf die anderen führt. Oder aber er geht vom Unterschied aus, setzt diesen jedoch sofort in die Begriffe der Superiorität und der Inferiorität um (in seinem Fall sind natürlich die Indianer die Unterlegenen): Man leugnet die Existenz einer wirklich anderen menschlichen Substanz, die eben nicht lediglich ein unvollkommenes Stadium der eigenen wäre. Diese elementaren Ausdrucksformen der Erfahrung mit dem Anderssein beruhen beide auf dem Egozentrismus, auf der Gleichsetzung der eigenen Werte mit den Werten allgemein, des eigenen Ichs mit dem Universum; auf der Überzeugung, daß die Welt eins sei. [...] Dieser Wunsch, die Indianer zur Übernahme der spanischen Sitten zu bringen, wird nie gerechtfertigt; er versteht sich von selbst. ${ }^{28}$
\end{abstract}

Was Todorov hier entwickelt, sind Grundformen einer Kippfigur, die in der tat die Beziehungen der Alterität oftmals - Todorov meint im Grunde immer - kennzeichnen. Entweder wir akzeptieren den anderen als gleichwertig, setzen ihn aber dann als mit uns identisch, löschen also seine Andersheit aus, indem wir ihn als Unseren betrachten. Oder aber wir verstehen ihn als anders, setzen ihn aber dann nicht auf dieselbe Ebene mit uns, und dies bedeutet in aller Regel, dass wir uns ihm überlegen fühlen. Im Zentrum dieser Auseinandersetzung steht also die Problematik des Anderen, der Alterität, des Umgangs der Europäer mit dem Fremden, dem Anderen, das ihm gegenübertritt. Die bange Frage, die dahinter steht: Haben wir wirklich etwas aus der Geschichte gelernt? Oder verfallen wir noch immer in dieselben Muster, wenn uns der Fremde, der Andere entgegentritt?

Selbstverständlich ist la question de l'autre eine Fragestellung, die nicht nur für die Begegnung der Europäer mit nicht-europäischen Menschen gilt, sondern auch auf andere Formen von Selbst- und Fremderfahrung übertragen oder doch zumindest kritisch angepasst werden kann. Sie gilt gerade auch in Bezug auf die Geschlechterbeziehungen, also mit Blick auf die Frage, wie sich

28 Todorov, Tzvetan: Die Eroberung Amerikas. Das Problem des Anderen. Aus dem Französischen von Wilfried Böhringer. Frankfurt a.M.: Suhrkamp 1985, S. 56 f. 
die Geschlechter wechselseitig wahrnehmen und inwieweit sich die Anerkennung von Alterität entwickeln kann, ohne doch - und ich meine: auf beiden Seiten - in ein Gefühl von wie auch immer gearteter, aber zumeist als moralisch artikulierter - Überlegenheit umzuschlagen. Sie merken: Hier geht es nicht mehr nur um Beziehungen im ausgehenden 15. Jahrhundert.

Alle diese Fragen haben also miteinander und vor allem auch mit uns zu tun. Der Romanist Karl Hölz hat einmal versucht, die geschlechterspezifische Dimension - im Übrigen keineswegs als erster - auf die Frage der Kolonialisierung anzuwenden und fruchtbar $\mathrm{zu}$ machen. ${ }^{29}$ Im Fortgang derartiger Forschungen halte ich es für ungemein spannend, diesen Gedanken einmal weiterzuspinnen, ebenso in Bezug auf den menschlichen Körper und die Unterwerfung menschlicher Körper in der Kolonialgeschichte insgesamt wie auch hinsichtlich der Problematik eines männlichen Blickes auf das von ihm unterworfene Weibliche, wie es sich in vielen Texten der Eroberer und Chronisten der Eroberung Amerikas darstellt und auch schon von Karl Hölz nachgewiesen wurde. Ich werde auf diese Fragestellung in diesem letzten Teil unserer Vorlesung noch mehrfach zurückkommen.

All dies sind sehr ernste Fragen, die zum Nachdenken anregen. Lassen Sie mich Ihnen aber an dieser Stelle ein eher lustiges Beispiel vorführen. Es ist das Beispiel einer interkulturellen Kulturbegegnung, die eigentlich keine war. Oder mehr noch: Sie beinhaltete eine Wahrnehmung von Alterität, von Fremdheit oder Andersartigkeit, die in einem völligen Mißverständnis endet. Denn auf seiner dritten Reise kam Christoph Columbus zur Küste der von ihm so benannten Insel Trinidad, und er wurde dort einiger Bewohner derselben gewahr und widmete ihnen seine Aufmerksamkeit. Einmal mehr stellte sich das Problem der Sprache, und Columbus glaubte in diesem Falle, einen Ausweg aus der Sackgasse gefunden zu haben: Er griff auf die internationale Sprache der Musik zurück. Aber hören wir hier diese Darstellung von der wohlgemerkt dritten, zwischen 1498 und 1500 stattgefundenen Reise des Admirals des Ozeanischen Meeres in seinen eigenen Worten:

El día siguiente vino de hazia Oriente una grande canoa con veinte y cuatro hombres, todos mançebos y muy ataviados de armas, arcos y flechas y tablachinas, y ellos, como dixe, todos mançebos de buena disposiçión y no negros, salvo más blancos que otros [...]. Cuando llegó esta canoa habló de muy lexos, y yo ni otro ninguno no los entendíamos, salvo que yo les mandava hazer señas que se allegasen; y en esto se passó más de dos oras, y si se llegavan un poco, luego se desviavan; yo les hazía mostrar baçines y otras cosas que luzían, por enamorarlos porque viniesen, y a cabo de buen rato se allegaron más que hasta entonçes no avían; y yo deseava mucho aver lengua, y no tenía

29 Vgl. Hölz, Karl: Das Fremde, das Eigene, das Andere. Die Inszenierung kultureller und geschlechtlicher Identität in Lateinamerika. Berlin: Erich Schmidt Verlag 1998. 
ya cosa que me pareciese que era de mostrarles para que viniesen, salvo que hize sobir un tamborín en el castillo de popa, que tañesen e unos mançebos que dançasen, creyendo que se allegarían a ver la fiesta. Y luego que vieron tañer y dançar, todos dexaron los remos y echaron mano a los arcos y los encordaron, y embraçó cada uno su tablachina y començaron a tirarnos flechas. Cessó luego el tañer y dançar, y mandé luego sacar unas ballestas; y ellos dexáronme y fueron a más andar a otra caravela, y de golpe se fueron debaxo la popa d'ella [. . .]; e nunca más los vide, ni a otros d'esta isla. ${ }^{30}$

Cristóbal Colón schildert hier ein interkulturelles Mißverständnis aus einer sehr präzise erfassten eigenkulturellen Position. In dieser Passage lässt sich daher eine ganze Reihe überaus interessanter Details finden, die uns viel über den Dialog zwischen Europäern und Nicht-Europäern aussagen.

Da ist zum einen die hier noch gekürzte sehr positive Beschreibung der Körper dieser jungen Indianer aus Trinidad, die selbst noch nicht wissen konnten, dass sie ganz einfach Indianer (sic) aus Trinidad (sic) waren. Ihre körperliche Erscheinung wird ebenso aus Gründen der späteren Nutzbarkeit als auch aus ästhetisch-rassistischen Gründen (sie haben geradezu weiße Körper, sind vor allem aber nicht schwarz) sehr positiv bewertet. Der Reisebericht beginnt also mit einer insgesamt positiven Annäherung an die Fremden, an die Anderen, die deutlich auch als solche gekennzeichnet werden.

Bemerkenswert ist auch die Beschreibung der stundenlangen vorsichtigen Annäherung beider Seiten, die geradezu als ein wechselseitiges Sich-Abtasten und Sich-Belauern verstanden werden kann. Dabei sind zunächst die Europäer in der aktiven Rolle, wollen sie doch die Indianer zu sich heranlocken und bieten dazu allerlei glänzenden Tand auf. Doch diese erste Kommunikationsphase scheitert: Man versteht sich rein sprachlich nicht. Dolmetscher, die zwischen beiden Gruppen vermitteln könnten, gibt es nicht: Die Spanier hatten zu diesem Zeitpunkt noch keine lenguas zur Verfügung. Daher beschließt Columbus, seine Suche nach nonverbalen Zeichensystemen jenseits konkreter Gegenstände fortzusetzen, und er kommt auf die schöne Idee, dass ja Musik gleichsam eine internationale Sprache ist.

So haben wir also die Musik als erste Form der Kommunikation zwischen Europäern und Eingeborenen auf der Insel Trinidad, eine Tatsache, die ein Musikologe von Trinidad in einem spannenden Vortrag sehr bewusst und zugleich ironisch herausstrich. In der Tat sollten auch künftig musikalische Verbindungen eine wichtige Rolle in Bezug auf Trinidad im Besonderen und die Karibik im Allgemeinen spielen - und dies ist gleichsam der Beginn dieser interkulturellen Relationen. Cristóbal Colón läßt also Tamburin schlagen und dazu einige

30 Colón, Cristóbal (1986): Los cuatro viajes. Testamento. Ed. de Consuelo Varela. Madrid: Alianza, S. $231 \mathrm{f}$. 
Matrosen tanzen. Das muß hübsch artig ausgesehen haben, wie da auf diesem großen Holzschiff plötzlich vielleicht nicht allzu gelenkige Seeleute einen Tanz zu rhythmischen Schlägen aufführten. Die Reaktion der Insulaner ließ nicht lange auf sich warten.

Wir werden nie genau erfahren, was die Eingeborenen davon hielten, sehen aber ihre unmittelbare Reaktion: Sie gfreifen sofort zu Pfeil und Bogen und setzen auf diese weise die Kommunikation zwischen beiden Seiten fort. Erneut greift Columbus zu einem nicht weniger nonverbalen Kommunikationsmedium, nämlich dem Zeigen überlegener Waffentechnik, eine Demonstration eigener Stärke mit Hilfe der Armbrust.

Es ist klar, dass nach dieser Begegnung musikalisch-militärischer Art ebenso der Zeichenvorrat als auch das Kommunikationsbedürfnis im Wesentlichen erschöpft sind. An dieser Stelle zeigt sich sehr deutlich die Hilflosigkeit beim Ausfall einer sprachlichen Kommunikation und zugleich die Fähigkeit, aufgrund überlegener Technik - etwa in Bezug auf die Schiffe, auf die Tauschformen, aber insbesondere auch in Bezug auf die ebenfalls überlegene Waffentechnik - stets die Situation im Griff zu haben und zu beherrschen. Das Ergebnis derartiger 'Begegnungen' ist aber, wie wir hier leicht erkennen können, die konfrontative Auseinandersetzung, der kriegerische Konflikt, der dann zumeist zuungunsten der Eingeborenen ausgeht.

Hatten die jungen und wehrhaften Indianer Musik und Tanz als Bedrohung interpretiert, vielleicht gar als einen Kriegstanz verstanden? Wir werden es nicht erfahren. Doch Columbus wurde in dieser Situation sicherlich klar, dass auch die Verwendung von Musik und der Rekurs auf dieses künstlerische Medium keineswegs eine von spezifischen Konventionen freie Sprache darstellt, ja dass selbst die besten Intentionen gänzlich anders gedeutet werden können. Vieles in der Begegnung der 'Zivilisierten' mit den 'Wilden' weist eine derartige Abfolge von Missverständnissen auf, die in dieser Szene gleichsam zeitlupenartig vorgeführt werden. Der Reisebericht wird hier erneut zu einem Medium ethnographischer und ethnologischer Feldforschung.

Auch sonst war Cristóbal Colón ein ausgezeichneter Beobachter, dem oftmals selbst kleinste Veränderungen etwa in der Natur nicht entgingen. So bewunderte Alexander von Humboldt Jahrhunderte später die äußerste Aufmerksamkeit, mit welcher Columbus von Klimaveränderungen im Bereich der karibischen Inseln berichtete. Der durch den Schiffbau der Spanier dramatisch erhöhte Holzeinschlag habe zu einer massiven Abholzung und Rodung ganzer Wälder geführt, was nicht ohne Rückwirkungen auf den Wasserhaushalt davon betroffener Karibikinseln geblieben sei. Plötzlich standen frisches Quell- und Trinkwasser auf den Inseln nicht mehr im ausreichenden Maße zur Verfügung. Columbus merkte diese Veränderungen an, doch erst viele Jahrhunderte später sollte sich eine 
Einsicht in die ökologischen Grundlagen entwickeln, in die der Mensch so brutal und kurzsichtig eingriff und eingreift. An dieser Stelle wird das Bordbuch in seinem Verhältnis von Reisen und Schreiben gleichsam prospektiv: Es wird erst lesbar, wenn viele Jahrhunderte vorüber gegangen sind und die Menschen aufmerksam wurden auf Phänomene, die in der damaligen Zeit nicht relevant erschienen.

Wenden wir uns an dieser Stelle kurz einem weiteren Italiener zu, nämlich Pietro Martire d'Anghiera, der nicht zuletzt auch unter seinem spanischen Namen Pedro Mártir de Anglería Berühmtheit erlangte und als ein Schriftsteller bekannt geworden ist, der im Grunde als erster die neuen Berichte - durch seine persönliche Vertrautheit mit nahezu allen wichtigen Protagonisten wie auch mit dem Königshof - in einen größeren Zusammenhang einzuordnen verstand. Ich möchte Ihnen im Folgenden einen Auszug aus einem in lateinischer Sprache verfassten Brief wiedergeben, den ich Humboldts Kritischen Untersuchungen $^{31}$ entnehme und der wohl vom Dezember 1493 stammt, also nur wenige Monate nach der Rückkehr des Columbus nach Spanien.

$\mathrm{Zu}$ diesem Zeitpunkt befand sich der Genuese freilich schon wieder auf hoher See, diesmal ausgestattet von den Katholischen Königen mit der größten ihm jemals anvertrauten Flotte an Schiffen und Menschen, unterwegs in die amerikanische Inselwelt der Antillen und im Vollbesitz seiner neuen Machtfülle als Admiral. In einer nur kurzen Einblendung folgt nun der Brief, der zugleich auch auf die ungeheure Freude verweist, welche die 'Entdeckungen' des Columbus in Spanien und Europa bei allen, die davon recht bald erfuhren, auslösten. Achten wir hierbei vor allem auf das Gefühl einer raschen Beschleunigung der Zeit, insofern fast jeden Tag neue Wunder geschehen würden, sowie auf eine Vergleichbarkeit der eigenen Zeitepoche wie der eigenen Erfahrungen mit der griechisch-römischen Antike:

Jeder Tag bringt uns neue Wunder aus jener Neuen Welt, von jenen Antipoden des Westens, die ein gewisser Genuese (Christophorus quidam, vir Ligur) aufgefunden hat. Unser Freund Pomponius Laetus (derselbe, welcher in Rom seiner religiösen Ansichten halber verfolgt wurde: bekannt als einer der ausgezeichnetsten Beförderer der klassischen römischen Literatur) hat sich kaum der Freudentränen enthalten können, als ich ihm die erste Nachricht von diesem unverhofften Ereignisse erteilte. [...] Wer von uns mag nun noch heutzutage über die Entdeckungen staunen, welche man dem Saturn, dem Triptolemus und der Ceres zugeschrieben hat? ${ }^{32}$

31 Vgl. Humboldt, Alexander von: Kritische Untersuchungen, Bd. 1, S. 29.

32 Bei Humboldt mit folgendem Zusatz in der Fußnote: Martire d'Anghiera, Pietro: Opus Epistolarum, Kap CLII, Amstelodami 1670, S. 84: „Prae laetitia prosiluisse te vixque a lacrymis prae gaudio temperasse, quando litteras adspexisti meas, quibus de antipodum orbe 
Wir haben uns nun ausführlich mit Christoph Columbus und weit darüber hinaus mit den Bedingungen und den historischen Kontexten seiner Zeit beschäftigt. Ich hielt dies für notwendig, weil wir in dieser Zeit eine Vielzahl von Grundlagen erkennen dürfen, die weit bis in unsere Zeit reichen und auch noch immer das Verhalten - vielleicht nicht mehr aller Staaten des sogenannten Westens, wohl aber ihrer großen multinationalen Firmen und Konsortien - prägen. Denn wir beuten die Welt noch immer aus.

In Columbus und seinem Reisebericht können wir die Grundlagen jener entscheidenden Asymmetrie zwischen Alter Welt und Neuer Welt, die in unserer Phase der Globalisierung umkodiert wurden in Asymmetrien zwischen Erster und Dritter sowie Vierter Welt, erkennen und zugleich verstehen, auf welche Weise und wie jeweils vermittelt die Erfahrungen und der Umgang mit der Alterität sich auch in unsere Epoche noch immer durchgepaust hat. Der Europäer Cristoforo Colombo ist - um es etwas überspitzt auszudrücken - noch nicht von seiner Bühne, ja von der Weltbühne abgetreten. Und wir wollen ihn damit keineswegs verantwortlich machen für all das, was an Kolonialismus, an Imperialismus, an Neokolonialismus nach ihm gekommen ist und sich noch immer perpetuiert. Er steht stellvertretend für vieles, was Europa in seinem Kern ausmacht. Nein, es ging mir hier keinesfalls um die Schaffung einer Negativfigur, die verantwortlich wäre für alles, was geschah. Ich habe vielmehr versucht, ihn in seiner Zeit durchaus positiv zu zeichnen und Ihnen ein verstehendes Bild des Genuesen zu liefern.

Aber der fortgesetzte koloniale Blick auf die unterschiedlichsten Gegenstände, Schätze und Vorkommen, die bisweilen auch mit den besten Absichten zu findende Meinung, man verstünde es besser als die Bewohner vor Ort und würde in ihrem Namen sprechen können, ja selbst die Frage der Restitution von Kulturgütern, die wir uns auf dubiose Weise angeeignet haben, zeigen die Latenz einer historischen Epoche, in der - Alexander von Humboldt paraphrasierend - binnen weniger Jahre die Verteilung der Gewalt und Macht über die Erdoberfläche entschieden wurde. Genau dies ist die große Zeit des Columbus.

Ich möchte Ihnen nun gegen Ende unserer Beschäftigung mit dem sogenannten 'Entdecker' der Neuen Welt, zu dessen Figur und Aktion wir freilich im

latenti hactenus te certiorem feci, mi suavissime Pomponi, insinuasti. Ex tuis ipsis litteris colligo, quid senseris. Sensisti autem, tantique rem fecisti, quanti virum summa doctrina insignitum decuit. Quis namque cibus sublimibus praestari potest ingeniis, isto suavior? quod condimentum gratius? ex me facio conjecturam. Beari sentio spiritus meus, quando accitos alloquor prudentes aliquos ex his qui ab ea redeunt provincia (Hispaniolae insula). Implicent animos pecuniarum cumulis augendis misere avari: nostras nos mentes, postquam Dei aliquando fuerimus, contemplando, huiuscemodi rerum notitia demulceamus.“ 
Verlauf der Vorlesung immer wieder zurückkehren werden, einen Brief vorstellen, der uns über den Verlauf der dramatischen vierten Reise des Columbus informiert. Es war bekanntlich die Reise, die Columbus mit besonders großen Erwartungen angegangen war, eine Reise, bei der aber zugleich offen zutage trat, daß der umstrittene Admiral der Katholischen Könige nach allen rechtlichen Auseinandersetzungen und Kämpfen nicht mehr die Kraft besaß, um sich wirklich noch mit seinen Zielen und Visionen durchzusetzen.

Doch seine Visionen waren stärker als jemals zuvor. Sie beherrschten ihn. In einer wirklich verzweifelten Situation, festgehalten auf Jamaica, wo er nun nicht mehr über Schiffe verfügte, sondern darauf hoffen musste, dass zwei seiner Männer sich mit einem Kanu nach Santo Domingo, nach der Insel Hispaniola durchschlagen könnten, um Hilfe und Verstärkung zu holen, schrieb er am 7. Juli 1503 einen Brief, der wegen seiner Seltenheit auch als Lettera Rarissima bezeichnet worden ist. Doch das Schreiben verdient seine Bezeichnung auch in der anderen, seltsamen Bedeutungsnuance des Raren. Der Brief ist folglich in vielerlei Hinsicht äußerst selten und seltsam, gewährt er uns doch Einblick in den Menschen Cristóbal Colón, der uns hier mit seiner ganzen visionären Kraft und seiner fundamentalen Abgründigkeit entgegentritt. Ich möchte Ihnen gerne mehrere kurze Passagen aus dem Schlussteil dieses Briefes präsentieren:

Cuando yo descubrí las Indias, dixe que eran el mayor señorío rico que ay en el mundo. Yo dixe del oro, perlas, piedras preciosas, espeçerías, con los tratos y ferias, y porque no pareçió todo tan presto fui escandaliçado. Este castigo me hace agora que no diga salvo lo que yo oigo de los naturales de la tierra. De una oso dezir, porque ay tantos testigos, y es que yo vide en esta tierra de Beragna mayor señal de oro en dos días primeros, que en la Española en cuatro años, y que las tierras de la comarca no pueden ser más fermosas ni más labradas ni la gente más cobarde, y buen puerto y fermoso río defensible al mundo. [...] Genoveses, venecianos y toda la gente que tenga perlas, piedras preçiosas y otras cosas de valor, todos las llevan hasta el cabo del mundo para las trocar, convertir en oro. El oro es excelentíssimo; del oro se hace tesoro, y con él, quien lo tiene, haçe cuanto quiere en el mundo, y llega a que echa las ánimas al Paraíso. [...] David en su testamento dexó tres mil quintales de oro de las Indias a Salomón para ayuda de edificar el Templo, y según Josepho era él d'estas mismas tierras. Hierusalem y el monte Sion ha de ser reedificado por mano de cristiano; Quién a de ser, Dios por boca del Propheta en el déçimo cuarto Psalmo dice. [...] ¿Quién será que se ofrezca a esto? Si Nuestro Señor me lleva a España, yo me obligo de llevar con el nombre de dios en salvo esta gente que vino conmigo; an pasado increíbles peligros y trabaxos. [...] aislado en esta pena, enfermo, aguardando cada día por la muerte y cercado de un cuento de salvajes y llenos de crueldad y enemigos nuestros, y tan apartado de los Sanctos Sacramentos de la Sancta Iglesia, que se olvidará d'esta ánima si se aparta acá del cuerpo. Llore por mí quien tiene caridad, verdad y justiçia. Yo no vine a este viaje a navegar por ganar honra ni hazienda [. . . . ${ }^{33}$

33 Colón, Cristóbal: Los cuatro viajes, S. $292 \mathrm{ff}$. 
Hier tritt uns ein Columbus mit all seinen Widersprüchen, mit all seinen Gegensätzen entgegen, die durch keine wie auch immer geartete harmonisierende Sichtweise zu glätten oder gar auszuräumen wären. Ganz am Ende taucht jener Columbus auf, der noch im Kern des Menschen der Renaissance sich befindet, ein Mensch, der versucht, sich auf dem Stand des Wissens und der Wissenschaft seiner Zeit zu halten, stets bereit, die erzielten Kenntnisse noch weiter zu treiben, sich und seine Männer immer weiter voranzutreiben um jener Kenntnisse willen, welche die geistige, räumliche und materielle Expansion Europas begründeten. Eine Expansion, die im Sinne dessen, was wir heute den Westen nennen, noch immer anhält.

Zugleich haben wir es hier mit einem Columbus zu tun, der das Hohelied des symbolisch so stark aufgeladenen Goldes singt, weil er letztlich hierin die einzige Möglichkeit erblickt, Jerusalem aus der Fremdherrschaft zu befreien, den Tempel wiedererrichten $\mathrm{zu}$ lassen und Gott in der Höhe $\mathrm{zu}$ lobpreisen. Doch stoßen wir hier nicht auf den Menschen des Mittelalters, auf jenen gläubigen und fanatischen Christen, der alles in der Welt symbolhaft deutet und alles tun will, was die Ehre seines Gottes vergrößert? Die Fahrt gen Westen, diente sie also letztlich doch, wie vermutet worden ist, der Reise nach Jerusalem, mithin der Fortführung eines Kreuzzuges nun mit anderen, neuen Mitteln? Mit Mitteln, die auf einer Finanzierung mit dem Gold der Amerikas beruhten, die es also ermöglichen würden, die Wucht der Eroberungen im Westen wieder nach Osten, in den Mittelmeerraum umzukanalisieren, um hier die Heilige Stadt und das Reich Gottes neu zu begründen?

Christoph Columbus sah sich auch in dieser Frage einmal mehr als Vollstrecker des göttlichen Willens - und befand sich zugleich doch in einer ausweglosen Lage, aus der ihn nur noch der Wille eben dieses Gottes befreien könnte. Die durchgängige Obsession des Goldes wird vom Genuesen gleichsam christlich begründet und sublimiert, eine Verbindung, die sich durchaus nicht nur bei Columbus findet. Denn wir stoßen an dieser Stelle auf das maßlose Sendungsbewustsein eines Menschen, dem sehr wohl bewusst war, wie weitreichend seine eigene Tat war, die Tat der Begründung neuer Schifffahrtsrouten, neuer Verbindungen, die Öffnung einer ganzen Welt für die Bedürfnisse Europas. Hatte er als Admiral aller Ozeanischen Meere dazu nicht den goldenen Schlüssel in der Hand?

Lesen wir diese Zeilen, so will es scheinen, als ob es ihm in den Konsequenzen seiner Entdeckungen ganz und gar nicht um die Entdeckung einer Neuen Welt ging, sondern um die Entdeckung einer Alten, um die Belebung nicht einer neuen Ordnung, sondern um die Wiederbelebung einer alten, die es nur neu aufzubauen galt. 
Just an dieser Stelle glimmt erneut der grundlegende Widerspruch im Leben und Denken des Columbus auf, an dem sich die wissenschaftlichen Kommissionen gerieben hatten, die sein Projekt für abwegig hielten, und der ihn zugleich in die Lage versetzte, gegen die geltenden Vorstellungen und gültigen Normen sowie die damals abschätzbaren Wahrscheinlichkeiten zu verstoßen, um seine auf fehlerhaften Berechnungen beruhende Tat auszuführen. Vor den bitteren Konsequenzen seiner fehlerhaften Berechnung des Erdumfangs rettete ihn allein, dass ihm auf halbem Wege ein neuer Kontinent mit seinen Inseln, Amerika, entgegen kam. Verstanden hat er dies Zeit seines Lebens nicht.

Doch die Fahrt gan Westen erscheint aus der Sicht der Lettera Rarissima nun als eine Tat, die von Europa aus für Europa gedacht war, letztlich die Christenheit als eine Einheit verstand, welche zu ihrem Zentrum, zu ihrem Mittelpunkt zurückkehren müsse: ins Heilige Land, nach Jerusalem. Ein wahrhaft seltsamer, nicht nur seltener Brief, den uns Columbus hier von Jamaica aus schreibt, eben jenem Jamaica, von dem aus Simon Bolívar seinen Brief, seine Carta de Jamaica, schreiben sollte, der uns noch in dieser Vorlesung beschäftigen wird. Es ist schon erstaunlich, wie immer wieder die Bewegungen Europas aus Europa herausführen und wie in gewisser Weise Europa sogar sein eigentliches Zentrum außerhalb seines eigenen Territoriums sucht. Die Idee von Europa, die räumliche Verortung seines Mythos außerhalb dessen, was wir heute als Europa kennen, der Raub der Europa in Tateinheit mit erzwungener Deportation und Vergewaltigung: All dies deutet an, dass Europa die unstillbare Bewegung ist, die nicht zur Ruhe kommt. Die Sehnsucht Europas nach einem Zentrum erscheint aus dieser Perspektive seltsam dezentriert. 